Active Duty Women's Perceptions of Breastfeeding

Support in the Military Setting

\author{
Sarah Elizabeth Martin
}

Chandler, Texas

Bachelor of Science in Nursing, The University of Texas at Tyler, 1998

Master of Science, The University of Colorado Health Sciences Center, 2007

\begin{abstract}
A Capstone Presented to the Graduate Faculty of the University of Virginia in Candidacy for the Degree of Doctor of Nursing Practice
\end{abstract}

\author{
School of Nursing \\ University of Virginia
}

June 2014

Emily Drake, PhD, RN

Mary Gibson, PhD, RN

Carrie Ann Litke, DO

The views expressed in this capstone are those of the author and do not reflect the official policy or position of the United States Air Force, Department of Defense, or the U.S. Government. 


\section{Abstract}

BACKGROUND

The purpose of this capstone is to evaluate the current perceptions of breastfeeding support for active duty women serving in the US Armed Forces to identify barriers to breastfeeding duration and to help assess current lactation policies and programs throughout the Department of Defense.

\section{METHODS}

An online survey based on the Workplace Breastfeeding Support Scale (WBSS; Bai, Peng, \& Fly, 2008) was used to collect data from active duty military mothers. A Facebook social media page was created to describe the survey, discuss desired outcomes and uses of the information obtained, and provide a direct link to the survey. Data was collected and analyzed using SPSS software to evaluate active duty women's perceptions of breastfeeding support in the military.

\section{RESULTS}

Three hundred and eighteen active duty women participated in the online survey. The average Workplace Breastfeeding Support Scale scores for active duty women was $50.20(S D=15.75)$. Comparing WBSS scores and branch of service, women in the Army had significantly lower WBSS scores $(M=45.85)$ then women in the Air Force $(M=53.96, p<.001)$. Enlisted women had significantly lower scores $(M=47.12)$ than officers $(M=54.62, p<.001)$. Also noted were significantly lower scores of active duty women who were Hispanic $(M=44.30)$ and women who had lower levels of education $(M=46.90, p=.006)$. Initial qualitative analysis revealed a lack of time and a place to pump/breastfeed, unsupportive supervisors and co-workers, and duty requirements as significant barriers to continuation of breastfeeding among active duty mothers. 


\section{CONCLUSIONS}

The goal of this capstone is to evaluate the perceptions of breastfeeding support in the active duty population to identify barriers to achieving breastfeeding goals among military mothers. The Department of Defense may be able to improve breastfeeding rates for all active duty mothers by implementing and adhering to lactation policies and focusing support efforts for enlisted women in all branches of service.

Keywords: Breastfeeding, military, policy, support 
Dedication

This project is dedicated to my loving husband, Ben, and my two wonderful children Charlotte and Isaac. I'm so grateful for your love, support, and encouragement! Thank you! 


\section{Acknowledgements}

I am so honored to have attended the University of Virginia School of Nursing for my DNP. I am forever grateful for the support, guidance, and mentorship provided by the nursing staff and fellow students who have taken this journey with me. I would especially like to thank Dr. Emily Drake, PhD, my advisor and capstone chair, Dr. Dorothy Tullmann, PhD, DNP program coordinator, Dr. Laura Yoder, PhD, Dr. Carrie Ann Litke, DO,Dr. Mary Gibson, PhD, and Robyn Roche-Paull, RN, IBCLC, for your feedback and guidance on this important project. I also want to thank all the active duty military mothers who participated in this survey. Thank you!! 
Table of Contents

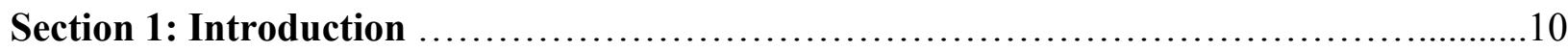

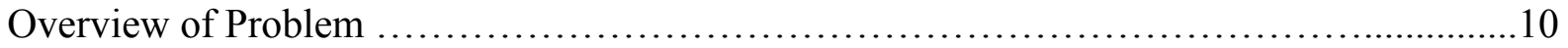

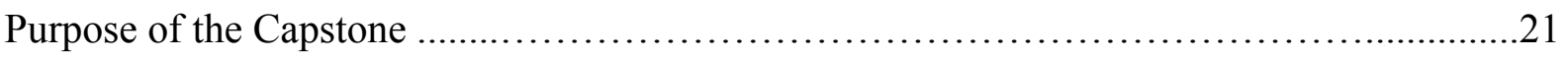

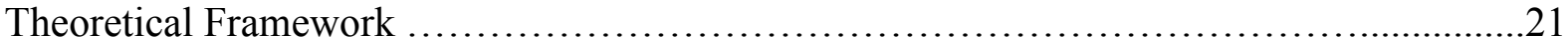

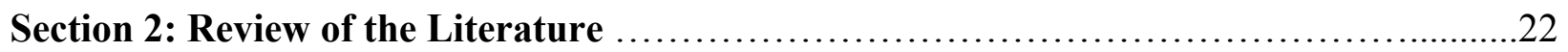

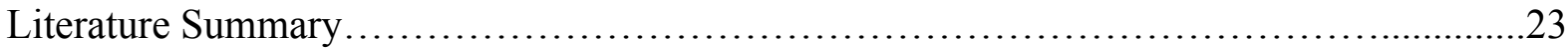

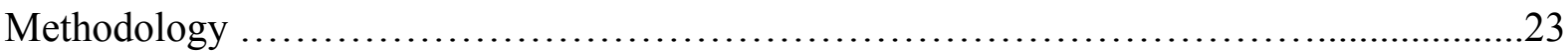

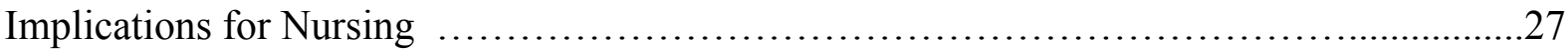

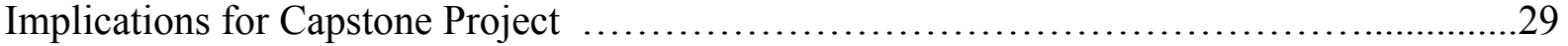

Rationale for Capstone Based on Review of the Literature ..................................29

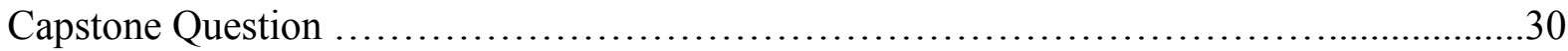

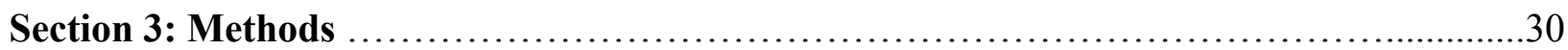

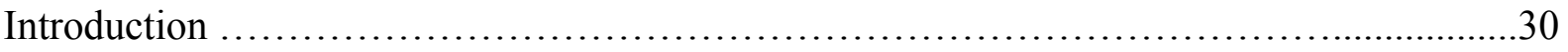

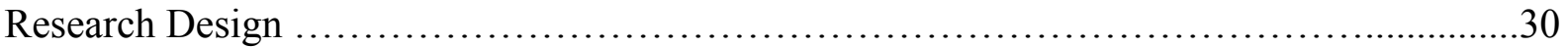

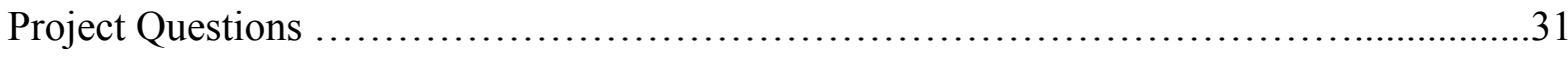

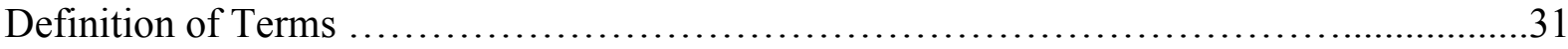

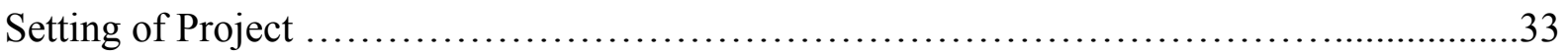

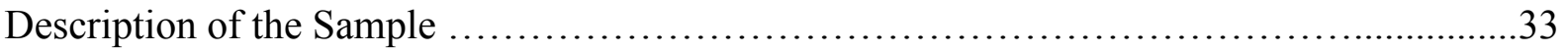

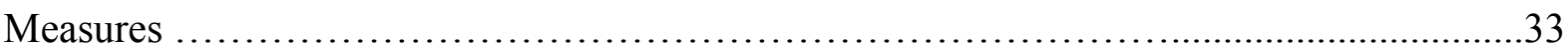

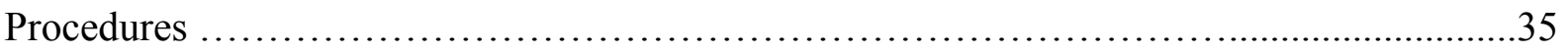

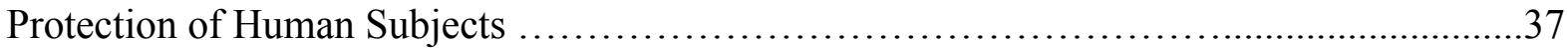




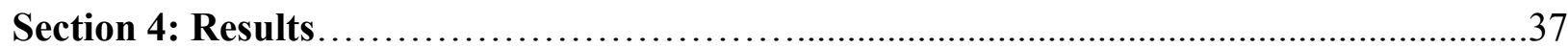

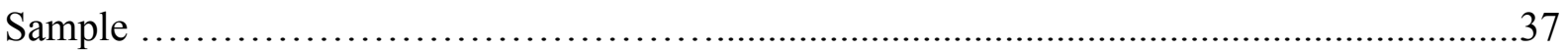

WBSS Scores and Selected Demographic Variables ...............................................39

WBSS Scores and Military Service ....................................................40

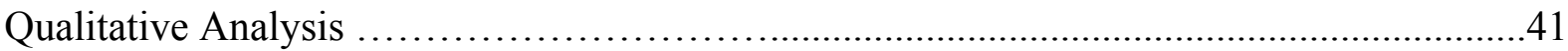

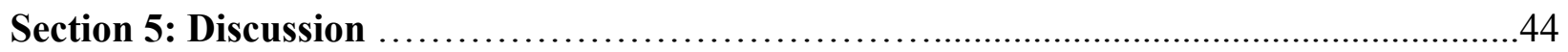

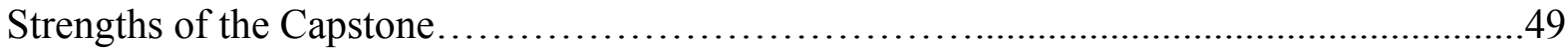

Weaknesses of the Capstone ....................................................................49

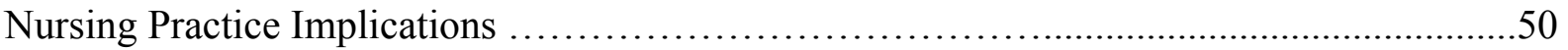

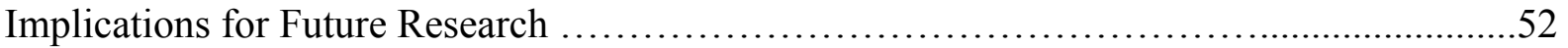

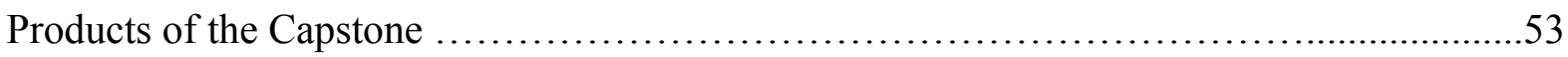

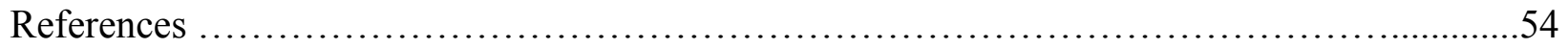

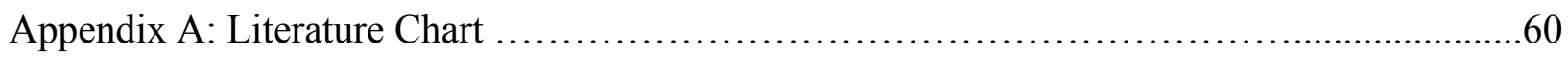

Appendix B: Permission Letter from WBSS Developer...................................................65

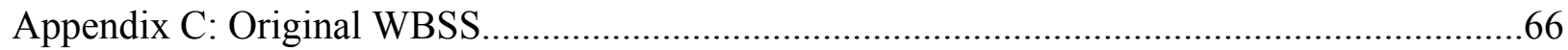

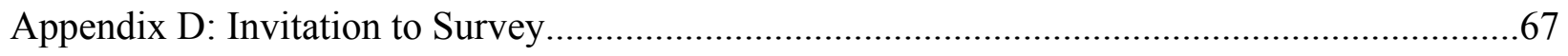

Appendix E: Survey Monkey Permission Letter............................................................68

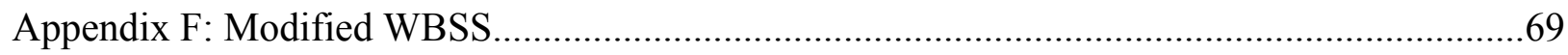

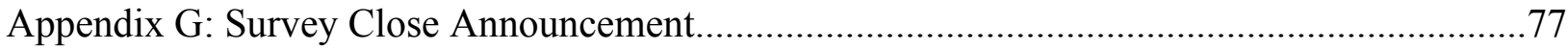

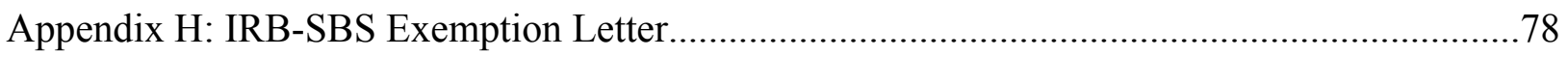

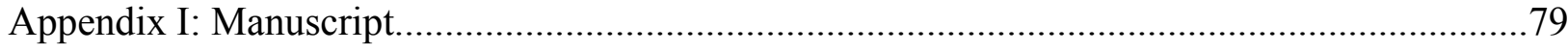


List of Tables

Table 1. Healthy People 2020 Target Goals...................................................101

Table 2. Morbidity Risk Reduction for Breastfed Infants/Children ...........................102

Table 3. Summary of Military Breastfeeding Policies.................................................................103

Table 4. Summary of Participant Demographics..................................................................104

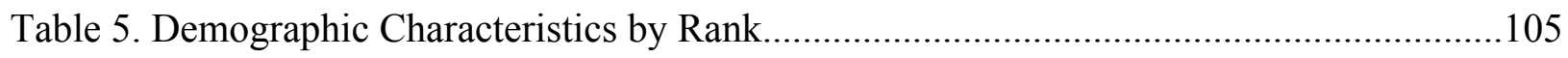

Table 6. Demographic Characteristics by Branch of Service.......................................................106

Table 7. Estimated Marginal Means of WBSS Scores..............................................................107

Table 8. Comparison of WBSS Scores per Question................................................................108 


\section{List of Figures}

Figure 1. Pender's Health Promotion Model ..................................................109

Figure 2. Summary of Literature Review Process................................................................110

Figure 3. Participant Inclusion and Exclusion Criteria..........................................................111

Figure 4. Consort Diagram for Two-Way ANOVA...............................................................112

Figure 5. Line Graph of Estimated Marginal Means..............................................................113

Figure 6. Summary of WBSS Scores per Question....................................................................114

Figure 7. Summary of Demographic Characteristics of Active Duty Women with Lower

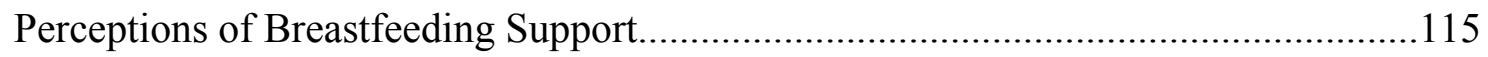


Active Duty Women's Perceptions of Breastfeeding Support In the Military Setting

\section{Introduction}

\section{Overview of Problem}

Breast milk is considered the "gold standard" of infant and child nutrition due to overwhelming scientific evidence supporting the health benefits for both mother and child (Eidelman \& Schanler, 2012). The increasingly acceptable social norms of breastfeeding in the US have helped create an upward trend in breastfeeding rates in the past decade. The significant increase in breastfeeding initiation rates, however, is overshadowed by the rapid decline in breastfeeding rates at six and twelve months (Bettinelli, 2012). The return to work after maternity leave is thought to contribute to the cessation of breastfeeding for many mothers due to an unsupportive work environment. Difficulty finding break time and a private place to express milk are often cited as the reasons for discontinuation of breastfeeding after returning to work (Feldman-Winter, 2013).

According to a survey prepared by the National Center for Veterans Analysis and Statistics (2011), a higher percentage of women Veterans ages 25 to 34 have children (59\%) compared to non-Veteran women of the same ages (52\%). Women who are serving on active duty face similar breastfeeding issues as the general population in addition to having many other unique challenges specific to military employment. Long duty hours, inflexible work schedules, and frequent separations from baby and family can make it difficult for active duty mothers to continue breastfeeding after returning to work (Roche-Paull, 2010). The Department of Defense (DoD) recognizes the importance of breastfeeding and has endorsed Healthy People 2020 target goals for health promotion and disease prevention (DoD Instruction 1010.10, 28 April 2014). 
However, a DoD wide lactation policy does not exist. Therefore, each branch of service has implemented lactation policies or support recommendations for their respective service members in an effort to support breastfeeding and optimize the health of military members and their families.

History of breastfeeding. The tug-of war between breast and bottle has been going back and forth for the past century. Infant formula was once thought to be "as good as" breast milk, a more convenient method of feeding, and a reflection of higher socioeconomic status (Thullier, D., 2009). However, formula feeding has been challenged over the past decade due to the myriad of scientific evidence showing the many short-term and long-term benefits of breastmilk and breastfeeding to both mother and child (Eidelman \& Schanler, 2012). Although public opinion recognizes the superiority of breast milk compared to formula, public support and breastfeeding culture in the United States seem to be lagging behind. Nowhere is this more evident than the lack of breastfeeding support in the work place (Feldman-Winter, 2013).

Benefits of breastfeeding. Due to myriad health benefits for both mother and child, Healthy People (HP) 2020 recommends an increase in total breastfeeding rates from birth to 1 year with a target goal of $81.9 \%$ after birth (initiation rates), $60 \%$ at 6 months and $34 \%$ at 1 year (www.healthypeople.gov). Exclusive breastfeeding rates are also included with target goals of $44.3 \%$ at 3 months and $23.7 \%$ at 6 months. To help achieve breastfeeding target goals, a worksite lactation support increase from $23.7 \%$ (2009) to $38 \%$ has also been set forth by HP 2020. See Table 1 for a summary of 2009 breastfeeding rates and the Healthy People 2020 breastfeeding goals. Mothers who breastfeed have both short and long term health benefits to include faster recovery and involution of the uterus after delivery, less incidence of postpartum 
depression, an increase in child spacing due to absence of ovulation, and faster weight loss (Eidelman \& Schanler, 2012). There is also an inverse relationship between the duration of breastfeeding and risk reduction of diseases such as Type II diabetes, breast, and ovarian cancer in women (Ip et al., 2007). To summarize, the longer the duration of breastfeeding, the less risk women have of having many diseases later in life.

For breastfed infants, the health benefits are even more profound (Eidelman \& Schanler, 2012). There is a significant reduction in many infant and childhood illnesses for breastfed infants such as ear and respiratory infections, gastrointestinal disorders, skin infections, allergies, obesity, diabetes, leukemia, and sudden infant death syndrome (SIDS) (Eidelman \& Schanler, 2012). Furthermore, there is growing evidence that shows a significant relationship with breastfeeding duration and improved long-term neurodevelopment for both term and preterm infants (Binns, James, \& Lee, 2013). An observed outcome for children who were exclusively breastfed for at least three months after birth is higher intelligence scores. Table 2 includes a list of common childhood illnesses and the risk reduction for infants and children who are exclusively breastfed for at least three months or longer.

Due to significant health benefits for mother and child, employers benefit from breastfeeding as well. According to Bartick \& Reinhold (2010), there is a potential cost savings of $\$ 3.6$ billion if breastfeeding rates were increased according to Healthy People 2020 recommendations. The American Academy of Pediatrics (AAP) released a cost analysis further describing the benefits to employers such as reduced absenteeism to care for ill children, lower health care costs on average, improved employee productivity, higher morale and greater employee loyalty, and an overall family-friendly image in the community (2010). Therefore, it is 
in the best interest of employers and the military to promote breastfeeding within their organizations.

Breastfeeding recommendations. Nationally recognized professional organizations provide recommendations for breastfeeding and guidance for breastfeeding support programs including the AAP, the American College of Obstetricians and Gynecologists (ACOG), the American Academy of Family Physicians (AAFP), Association of Women's Health, Obstetric and Neonatal Nurses (AWHONN), the American Dietetic Association, the American College of Nurse Midwives (ACNM), and the American Public Health Association (APHA). Because of the scientific evidence proving the benefits of breast milk, each of these organizations has recommended breast milk over formula. The official recommendation of the AAP is "exclusive breastfeeding for about 6 months, followed by continued breastfeeding as complementary foods are introduced, with continuation of breastfeeding for 1 year or longer as mutually desired by mother and infant" (Eidelman \& Schanler, 2012, p.828). The U.S. Department of Health and Human Services (USDHHS) has included breastfeeding among the national Healthy People objectives for the nation since 1990. In addition, the USDHHS Surgeon General, Regina M. Benjamin, released The Surgeon General's Call to Action to Support Breastfeeding (2011). This is a detailed and comprehensive report on the importance of breastfeeding, the health benefits for mother and child, national trends, barriers to breastfeeding, and recommendations to promote and support breastfeeding.

Breastfeeding support. In recognition of the importance of breastfeeding, support and education programs have been implemented in businesses, hospitals and birthing centers across the country (Thulier, 2009). Large-scale breastfeeding programs that are both nationally and 
globally recognized give guidance to employers and hospitals seeking to promote breastfeeding (www.babyfriendlyusa.org). Small-scale breastfeeding education and support programs led by nurses, breastfeeding educators, and International Board Certified Lactation Consultants (IBCLCs) have also been successfully implemented at the facility level (Bonuck, Trombley, Freeman, \& McKee, 2005; Mills, 2009).

The Ten Steps to Successful Breastfeeding is a global health initiative originally introduced in 1991 by Baby-Friendly USA (BFUSA) in an effort to promote breastfeeding support in birthing centers and hospitals around the world. The Ten Steps program is part of the Breastfeeding Health Initiative (BFHI) and is supported by the World Health Organization and the United Nations Children's Fund (WHO/UNICEF) (www.babyfriendlyusa.org). Healthcare facilities are recognized and endorsed as "Baby-Friendly" by meeting the criteria set forth by the Ten Steps program, which primarily include implementing breastfeeding friendly policies, educating staff, and supporting mothers in reaching their breastfeeding goals. Endorsed by the AAP, the Ten Steps program has been implemented in civilian and military health facilities globally in an effort to increase breastfeeding rates and assist women in achieving their breastfeeding goals.

Many government agencies have put forth strategies on how to promote and support breastfeeding in various settings. The Surgeon General's Call to Action to Support Breastfeeding (U.S. Department of Health and Human Services, Office of the Surgeon General, 2011) and the Center for Disease Control and Prevention (CDC) have outlined breastfeeding support strategies for healthcare institutions, employers, and communities (Breastfeeding Report Card- United States, 2013). The Business Case for Breastfeeding is a compilation of various education tools 
and strategies to help employers support breastfeeding employees (U.S. Department of Health and Human Services, Health Resources and Services Administration (HRSA), 2008). The United States Breastfeeding Committee (USBC) has also constructed a list of strategies that employers can use to support working mothers in achieving their breastfeeding goals (2010).

Despite the global, national, and organizational efforts to promote breastfeeding, rates still fall short of Healthy People 2020 goals and rapidly decline after women return to work (Murtagh \& Moulton, 2011). Women who are serving on active duty in the United States armed forces comprise a select population of the workforce that commands particular attention in regards to breastfeeding support (Stevens \& Janke, 2003). Even with various breastfeeding support programs currently in place in many military organizations, little is currently known about the perception of breastfeeding support for active duty women and how these programs have affected breastfeeding rates.

Breastfeeding policies. In recognition of the millions of women who return to work after delivery, legislation has been implemented promoting breastfeeding support in the workplace. The Patient Protection and Affordable Care Act (PPACA), includes a provision that provides support for working breastfeeding mothers (Murtagh \& Moulton, 2011). Section 4207 of the PPACA (2010) amends the Fair Labor Standards Act (FLSA) of 1938 by requiring all employers to provide a "reasonable break time" to express milk in a clean, private location other than a bathroom (http://www.govtrack.us/congress/bills/113/hr1941). Although the amendment of the FLSA is a positive step for promoting breastfeeding among working women in the U.S., similar policies and regulations have yet to be passed within the Military Health System (MHS) (Buckler, 2011). The program known as TRICARE provides active-duty and other eligible military 
persons with medical and dental coverage (Buckler, 2011), but is not traditional insurance that is familiar to the general population. The PPACA, passed into law in 2010, had no direct effect on the MHS or it's constituents. TRICARE is under the direct authority of the DoD and the Secretary of Defense, therefore laws that affect health care coverage for the majority of Americans do not affect active duty military members or their dependents that are covered under TRICARE (www.tricare.mil/preventivecare). Ultimately, military policies promoting breastfeeding are not affected by the PPACA, creating disparities in breastfeeding rates between active duty mothers and the general population (Buckler, 2011).

An important consideration to lactating mothers returning to work is the availability of a breast pump and pump supplies. The PPACA requires that private insurance companies cover the costs of breastfeeding support, supplies, and counseling; entitlements that do not extend to TRICARE beneficiaries. TRICARE coverage does provide mothers with "hospital-grade electric breast pumps", but only for "mothers whose infants were born prematurely (prior to 36 weeks) while the infant is in the hospital in the immediate postpartum period" (Tricare Policy Manual 6010.57-M, 1 February 2008). After the infant is discharged from the hospital, breast pumps and supplies are no longer covered under TRICARE unless the discharging provider writes a prescription in particular cases. The lack of TRICARE coverage of breast pumps and pump supplies for TRICARE beneficiaries is especially concerning for active duty mothers who must return to work after six weeks maternity leave.

Military breastfeeding policies. The Surgeon General's Call to Action to Support Breastfeeding (2011) and the American Academy of Family Physicians (AAFP, 2014) have encouraged the DoD to develop and implement lactation policies and statements in support of 
breastfeeding. Although breastfeeding policies are not standardized across the DoD, each branch of service has developed their own breastfeeding policies or recommendations. The implementation and adherence to breastfeeding policies is delegated down the chain of command. See Table 3 for a brief summary of current lactation policies in the military.

The Army is the only branch of the military that does not have an official "breastfeeding policy" in place at this time; however, the Army Female Soldier Readiness Guide provides a section on supporting the breastfeeding soldier. This section states that it is critical to provide breastfeeding soldiers returning to duty with "space, time, and support" in order to facilitate the continuation of breastfeeding (Section X of the TG281; A Guide to Female Soldier Readiness). The Army also goes a step further and provides a Breastfeeding Support Plan Memorandum that female soldiers can provide to their Commander that provides guidance on current breastfeeding policies and recommendations and a breastfeeding work plan specific to the female member.

The Coast Guard has a breastfeeding policy in place that specifies that a private room is required for lactating women. Specifics regarding break times are not mentioned but it does encourage commanders and the member to communicate regarding their lactation needs. The Coast Guard has an additional policy (Section 12.F.1- Separation for the Care of a Newborn Policy) that gives the member (male or female) the option to separate from the Coast Guard service for up to 2 years without pay. They can then return to duty without losing rank, pay or benefits.

The Marine Corps breastfeeding policy states that a servicewoman who continues to breastfeeding upon returning to duty shall be provided a clean, secluded space (other than a 
toilet) with an available water source. Pumping break times are not discussed, but policy encourages members to communicate their lactation needs to their supervisor.

The Navy, similar to the Marine Corps, requires the availability of a clean, secluded space with running water for pump breaks. Specifics related to pumping times are to be coordinated between the member and the supervisor on a case-by-case basis. The Navy defers deployments up to 12 months ( 1 year) after delivery, which is the longest deferment of the military branches.

The Air Force recommends that supervisors provide lactating members with 15-30 minutes every 3-4 hours to breast pump in a clean, secluded space that is not a restroom. The usual 6 months deferment from deployment is mentioned with the caveat that AF commanders may defer deployments for up to 12 months postpartum "to ensure the full medical benefits of breastfeeding".

Breastfeeding in the military. As of September 2012, the United States military employed just over 204,000 women, making up approximately $14.6 \%$ of the active duty population (www.defense.gov). Prior to WWII, women in the military who became pregnant were given an involuntarily medical discharge for being "unfit for duty" (Ziobro, M., 2010). Today, however, over $99 \%$ of military specialties are open to women to include forward combat positions. The ability of women in the military to fulfill all duties alongside their male counterparts has been a huge step forward in recognition of women's contributions in the military. However, it has complicated cultural norms and policies regarding women's health and lactation in the work place. What was once an all male organization, the U.S. military is 
expanding policies to accommodate women in uniform regarding their health and privacy (DoD Report to the White House Council on Women and Girls, 1 Sept 2009).

Due to the growing evidence showing the health and financial benefits of breastfeeding for both mother and child (AAP policy statement on Breastfeeding and the Use of Human Milk, 2006, 2012; Bartick \& Reinhold, 2010) the DoD has taken many steps to promote breastfeeding amongst active duty mothers in the past decade. Like most civilian healthcare facilities, military perinatal units have transitioned from having traditional nurseries where baby is separated from mother after birth to the "rooming-in" concept, which has been found to promote breastfeeding (Moore \& Anderson, 2007). The Surgeon General's Call to Action to Support Breastfeeding (2011) has encouraged the acceleration of the implementation of the Baby-Friendly Hospital Initiative and The Ten Steps to Successful Breastfeeding in healthcare facilities throughout the US. Currently, 3 military hospitals (1-Army and 2-Navy) have even taken the necessary steps to be designated Baby-Friendly in accordance with the Baby-Friendly Hospital Initiative (BFHI) (www.babyfriendlyusa.org). Military healthcare facilities that are not officially designated as Baby-Friendly by the BFHI are still striving to meet the standards and recommendations put forth in The Ten Steps to Successful Breastfeeding in an effort to improve breastfeeding rates in military communities.

The breastfeeding support measures implemented by healthcare facilities are beneficial to promote breastfeeding initiation rates, however, research done in the general population shows little impact of long-term duration rates (Moore \& Anderson, 2007). Employer support of breastfeeding is essential to help mothers sustain breastfeeding and reach their long-term breastfeeding goals (Bar-Yam, 2004; Bai \& Wunderlich, 2013). The implementation of 
breastfeeding and lactation policies throughout the DoD is a solid effort to improve long-term breastfeeding rates for active duty women who desire to continue providing breast-milk to their infants after returning to duty. However, military lactation policies should be enforced from the top down at all levels of the chain of command as well as horizontally throughout the military's diverse career fields. The lack of uniformity and specificity of some military lactation policies can cause discrepancies in policy enforcement, leaving it up to the discretion of commanders and unit supervisors to provide lactation accommodations they see fit for female military members under their supervision.

There are several factors that could potentially have a negative impact on an active duty woman's perception of breastfeeding support and overall breastfeeding duration. Many job related issues that affect breastfeeding women in uniform are discussed in "Breastfeeding in Combat Boots: A Survival Guide to Successful Breastfeeding While Serving in the Military" written by Navy veteran Robyn Roche-Paull (2010). Rank structure can have a significant influence on breastfeeding duration depending on if you are an officer or an enlisted military member. "Enlisted personnel, especially junior enlisted have the hardest time with pumping at work, as you are at the mercy of the work schedule and your supervisor's needs" (Roche-Paull, 2010, p. 237).

The overall masculine culture of some military work environments can also have a negative impact on perceptions of breastfeeding support for some active duty mothers. Despite the increasing numbers of women in uniform, the military remains $85 \%$ male, therefore, requesting time and space to breast pump at work can be uncomfortable. "For both men and women, there is a mental shift to make from the everyday reality of being a soldier/sailor/airman 
to the obviously nurturing act of providing breast milk for your infant" (Roche-paull, 2010, p. 239). Depending the career field, the often "warrior-like" mentality of military co-workers and supervisors can provide an unsupportive environment for active duty lactating mothers. Furthermore, many male supervisors may be uncomfortable with the subject of breastfeeding, and many female supervisors may have feelings of anger or guilt over their own breastfeeding failures, therefore they may not provide the logistical unit support needed regarding break times and privacy for breastfeeding subordinates in uniform (Roche-Paull, 2010, p. 240).

Although it is understood that military service is voluntary and there can be unavoidable circumstances that inhibits long-term breastfeeding, most active duty mothers can still achieve their breastfeeding goals with widespread support and enforced lactation policies. "Women [in the military] have the right to have children as well as the right to breastfeed them" (Stevens \& Janke, 2003, p. 382).

\section{Purpose of the Capstone}

The purpose of this capstone is to evaluate the current perceptions of breastfeeding support for active duty women serving in the US Armed Forces, to identify barriers to breastfeeding, and to assess current lactation policies and programs throughout the DoD. The results can be used to help guide breastfeeding policy development and implementation, develop breastfeeding education materials for both breastfeeding women and supervisors, and close the gaps of breastfeeding support between military women and the general population.

\section{Theoretical Framework}

The theoretical framework that guides this capstone is the health promotion model (HPM) proposed by Nola J Pender in 1982 and revised in 1996. The HPM defines health as "a 
positive dynamic state not merely the absence of disease" (George, 2010, p. 210). Breastfeeding is a positive health behavior that can be influenced by many internal and external factors. Using the HPM as a guide, the research questions will evaluate external factors that can influence breastfeeding; specifically perceived support from employer. There are three propositions of the HPM that can greatly influence breastfeeding for active duty women (George, 2010, p. 215):

- Persons are more likely to commit to and engage in health-promoting behaviors when significant others model the behavior, expect the behavior to occur, and provide assistance and support to enable the behavior.

- Families, peers, and health care providers are important sources of interpersonal influence that can increase or decrease commitment to and engagement in healthpromoting behavior.

- Situational influences in the external environment can increase or decrease commitment to or participation in health-promoting behavior.

The assumption proposed by the HPM is that active duty women are more likely to continue to breastfeed after returning to work if they have the support from a breastfeeding friendly environment. The ultimate goal of breastfeeding promotion in military settings is to increase breastfeeding rates in the active duty military population that meets recommendations and goals set by the AAP and HP 2020. See Figure 1 for a diagram depicting Pender's HPM.

\section{Review of the literature}

Current military policies on breastfeeding attempt to increase the duration of breastfeeding for active duty mothers per national recommendations. Prior to conducting a capstone project to evaluate the current perceptions of breastfeeding support for active duty 
women, it was important to understand what research has already been done to evaluate breastfeeding promotion and policies in military communities and the effects on breastfeeding rates, specifically for active duty mothers.

\section{Literature Summary}

Methodology. Nursing and health care literature was examined by using the following search terms: breastfeeding, policy, support (breastfeeding), military. Databases that were searched were OVID MEDLINE, CINAHL, Cochrane, and PubMed via the University of Virginia Claude Moore Health Sciences Library website. Attention was focused on peerreviewed journals in women's health as well as military journals. Government websites sponsored by the DoD and TRICARE were also searched for breastfeeding policy and program information.

Inclusion criteria for articles were 1) Published in English, 2) Published from year 2000 to present, and 3) evaluation of any breastfeeding in US military populations to include active duty and non-active duty women. Excluded were reports that 1) were not published in English, 2) Published prior to the year 2000,3) Research that was not done in US military populations or focused on military women in other countries, and 4) Reports that only evaluated the experiences of breastfeeding for women in deployment situations. Recognizing that culture and available resources can have significant effects on breastfeeding rates was the primary reason articles that focused on breastfeeding women in other countries were not included in search criteria. Two articles were excluded that focused on continuation of breastfeeding for active duty women while deployed. Although this is an important aspect of breastfeeding in the military to consider, trying to maintain lactation while in deployed locations or separated from baby for other military 
required training provides unique challenges that are beyond the scope of recommendations for this capstone.

In addition to searching national databases, references were obtained from governmentsponsored websites such as the Center for Disease Control and Prevention (CDC.gov), U.S. Department of Health and Human Services (hhs.gov), and the Agency for Healthcare Research and Quality (ahrq.gov) using the same search criteria.

After performing an extensive review of the literature, seven total articles met inclusion criteria of evaluating breastfeeding support for active duty mothers in military settings: Two articles reviewed lactation policies and support services offered in military settings and evaluated the effectiveness on breastfeeding rates; two articles provided a qualitative analysis of the breastfeeding experiences of women delivering in military facilities; two articles provided quantitative analysis of breastfeeding rates in military settings; and one article provided a mixed quantitative/qualitative evaluation of breastfeeding rates in a military setting. See Figure 2 for a summary of the literature review process and Appendix A for a literature chart of reviewed articles that met inclusion criteria.

Summary of research articles. A two-part series by Bell and Ritchie (2003a, 2003b) evaluated breastfeeding policies, resources and support programs throughout the DoD. At the time this review was done, the Navy was the only branch of service that had an official breastfeeding policy in place. Therefore, a recommendation was made to establish written lactation guidelines throughout the $\mathrm{DoD}$ and increase in the lactation resources provided to all women who are covered by TRICARE. Recommendations also included: increasing the number of Full-time Lactation Consultants at MTFs, offering breastfeeding classes, increasing the 
amount of outpatient lactation support, and improving breastfeeding support in military work places targeting improved breastfeeding duration for active duty women.

A qualitative study done by Stevens \& Janke (2003) exploring the breastfeeding experiences of active duty women found that breastfeeding cessation was due primarily to many obstacles encountered after returning to work. The common themes found were duties requiring separation from baby; difficulty finding a place and time to pump while at work; common breastfeeding issues; and other military specific duties. Although results were not statistically significant due to the small sample size $(\mathrm{N}=9)$, clinically significant implications of work support on the duration of breastfeeding for active duty women were important for developing future military lactation policies.

A retrospective quantitative study examined the impact of International Board Certified Lactation Consultants (IBCLCs) on breastfeeding and continuation rates for up to six months in three military MTFs (Rishel \& Sweeney, 2005). This study, originally conducted in 2001, compared breastfeeding rates of women delivering in MTFs with and without the use of IBCLCs. They found that women who interacted with IBCLCs after delivery had significantly higher (98\%) breastfeeding initiation rates than women who did not interact with an IBCLC after delivery $(14.4 \%, p<0.0001)$. These results are consistent with more current research showing that IBCLCs can significantly improve breastfeeding rates (Feldman-Winger, 2013). In this study, both active duty and non-active duty women were surveyed and had comparable breastfeeding initiation rates at discharge. However, at 4 months and 6 months postpartum, significantly more active-duty mothers had stopped breastfeeding $(\mathrm{P}=0.038)$. Other statistically significant findings in this capstone were that mothers who were 27 years of age or older or had 
higher levels of education also had higher breastfeeding initiation and continuation rates $(p=$ 0.005 at discharge, $p=0.004$ at 4 months, $p=0.034$ at 6 months for age; $p=0.034$ at discharge, $p<$ 0.001 at 4 months, $p=0.017$ at 6 months for higher levels of education).

In 2006, an assessment of breastfeeding practices and reasons for success were conducted in a military community hospital (Haas, Howard, Christopher, Rowan, Broga, \& Corey, 2006). At different time intervals from 2002 to 2004, a cross-sectional survey was done before and after lactation services (IBCLCs and breastfeeding education) were established to assess breastfeeding rates in both active duty and dependent women. Higher education level was the only statistically significant factor that predicted long-term breastfeeding at six months postpartum $(p<.05)$. A clinically significant finding was that breastfeeding rates were much lower for active duty women at 6 months (53.3\%) than non-active duty women (66.3\%) despite having similar breastfeeding rates at 6 week postpartum $(73.8 \%, 74.1 \%$, respectively).

A combined qualitative/quantitative study by Uriell, Perry, Kee \& Burress (2009) evaluated breastfeeding rates in the active duty Navy population by adding breastfeeding specific questions to the annual 2005 Navy Pregnancy and Parenthood Survey. They concluded that most women in the Navy stopped breastfeeding after returning to work due to lack of time and a place to pump, however, there was no significant difference between officer and enlisted results ( $p>$ 0.05). The survey also included civilians who worked for the Navy as contractors or DoD employees. An important finding was that all civilian rates of breastfeeding (birth to 18 months) were significantly lower than active duty Navy rates of breastfeeding $(p<0.05)$. For example, $13 \%$ of active duty Navy women were breastfeeding at 6 months postpartum compared to $42 \%$ of civilian Navy employees. 
The most recent study to date that met inclusion criteria evaluated breastfeeding rates and factors relating to cessation in a military population (Bales, K., Washburn, \& Bales, J., 2012). A survey of active duty $(n=43,16.9 \%)$ and non-active duty $(n=211,83.1 \%)$ mothers done from October 2001 to October 2002 found a statistical significance between active duty and nonactive duty women and breastfeeding rates after 6 months $(\mathrm{p}<0.043)$. Of the active duty women surveyed, only $39.5 \%(\mathrm{n}=17)$ stated that they were able to breastfeed for 6 months or longer compared to non-active duty mothers $(56.5 \%, \mathrm{n}=118)$. The authors recommended that future research focus on breastfeeding rates of active-duty women to assess need for policy changes that would encourage and support continuation of breastfeeding after return to work.

\section{Implications for Nursing}

According to the American Nurses Association (ANA), "Nursing is the protection, promotion, and optimization of health and abilities, prevention of illness and injury, alleviation of suffering through the diagnosis and treatment of human response, and advocacy in the care of individuals, families, communities, and populations" (2013). Through breastfeeding promotion, support, and education, nurses can help women reach their breastfeeding goals and thus have a profound positive effect on the health of women and children.

Research has shown that breastfeeding is influenced by how much or how little breastfeeding support the family receives from care givers prior to discharge from the hospital (DiGirolamo, Grummer-Strawn, \& Fein, 2003). Military nurses at the bedside should be educated about breastfeeding and feel comfortable providing breastfeeding support and education to families prior to discharge from the hospital. Public health nurses in military settings play a key role in developing breastfeeding education programs in military healthcare 
facilities and organizations. In order to provide optimal support for breastfeeding women in uniform, military nurses should identify strengths and weaknesses of breastfeeding programs at each MTF and make improvements accordingly.

The reasons breastfeeding rates do not meet professional recommendations have been well researched. The Surgeon General's Call to Action to Support Breastfeeding (2011) has identified seven primary barriers to breastfeeding in the United States:

- Lack of Knowledge

- Social Norms

- Poor Family and Social Support

- Embarrassment

- Lactation Problems

- Employment and Childcare

- Barriers related to Health Services

This capstone assesses perceptions of breastfeeding support for active duty women in military settings, particularly after they return to work. The results should help nurses in military settings promote breastfeeding policies and programs that empower active duty military mothers to reach their breastfeeding goals.

On a grander scale, nurses have the power to influence health policy at the national level and within organizations. Advocacy for breastfeeding policies that promote and support breastfeeding is an important responsibility of nurses across the country. In the military setting, nurses should advocate for breastfeeding policies and support programs that will increase the duration of breastfeeding resulting in optimal health of active duty mothers and their children. 


\section{Implications for Capstone Project}

As long-term breastfeeding is becoming more socially acceptable in the US, lactation policies and programs are being implemented at local and national levels to ensure mothers are getting the support and resources they need to reach their breastfeeding goals. A previous study identified four key areas that promote duration of breastfeeding in women who return to work: 1) A space to pump/breastfeed, 2) Time to pump/breastfeed, 3) General support from supervisors, policies and programs in the workplace and from medical professionals, and 4) Gatekeepers who ensure that the women are given the opportunity to breastfeed (Bar-Yam, 2004). The PPACA and FLSA amendments provide employer guidance in these four key areas to improve breastfeeding rates for working women in the general population. Active duty women, however, are not covered by the PPACA and face unique military demands and responsibilities that can shorten the duration of breastfeeding. Evaluation of the perceived breastfeeding support by active duty mothers is important to understand what barriers persist and how to improve lactation support in military facilities. Promoting breastfeeding within the military population and providing active duty mothers with the lactation resources they need will keep military mothers and children healthy and reduce healthcare costs.

\section{Rationale for Capstone Based on Review of the Literature}

The review of literature shows that breastfeeding rates among active duty women are lower than breastfeeding rates in the general population at six and twelve months postpartum. The lack of breastfeeding support in the workplace was the primary reason indicated, however, the small numbers of active duty women participants warrants further research within this population. Evaluation of the perceptions of breastfeeding support is needed to identify gaps in 
policies and support programs throughout the $\mathrm{DoD}$ and guide efforts into improving breastfeeding rates for active duty women. See Appendix A for a literature chart of articles selected that evaluated breastfeeding in military communities.

\section{Capstone Question}

What are the current perceptions of breastfeeding support for active duty women in the military setting?

\section{Methods}

\section{Brief Introduction}

The increasing awareness of the health and financial benefits of breastfeeding has encouraged many military services to implement lactation policies and support programs in accordance with the US Surgeon General's Call to Action to Support Breastfeeding (2011). Current perceptions of the effectiveness of these policies and programs is needed to ensure active duty women are getting the breastfeeding support they need to improve duration rates. The aim of this capstone is to evaluate the perceptions of breastfeeding support in the workplace for active duty women to identify gaps and provide recommendations that can improve current policies and support programs.

\section{Research Design}

A cross-sectional survey design was used to assess breastfeeding support in the military. Questions for the survey were adapted from the Workplace Breastfeeding Support Scale (WBSS), a short questionnaire designed to measure mothers' perceived support for breastfeeding from the workplace that has been tested and proven acceptable for both reliability $($ alpha $=.77)$ and validity (Bai, Peng, \& Fly, 2008). Responses are measured on a 7-point Likert scale with a high 
score indicating a more positive perception of workplace breastfeeding support. The lowest possible score is 12 and the highest possible score is 84 . After receiving permission via e-mail from the WBSS developer, the 12 question WBSS in addition to 10 demographic questions and 1 open-ended question were incorporated into a Survey Monkey online survey tool. See Appendix B for the WBSS permission e-mail from the developer.

\section{Project Questions}

The key outcomes of the capstone were to assess the overall perception of breastfeeding support for active duty women, identify if disparities exist in perceptions of breastfeeding support for certain groups, and evaluate the effectiveness of current lactation policies and programs in promoting breastfeeding within the military community. Comparing WBSS scores with demographic information is useful to help guide breastfeeding promotion efforts for active duty women. Due to the paucity of research done on breastfeeding support for active duty women, this capstone aims to provide a foundation for future breastfeeding research in the active duty population.

\section{Definition of Terms}

Department of Defense (DoD)- America's largest government agency that overseas both civilian and military government operations. The DoD manages an inventory of installations and facilities to keep Americans safe. (www.defense.gov)

TRICARE- health entitlement program for military members and their families. TRICARE is managed by the Defense Health Agency (DHA) under the policy guidance and direction of the Assistant Secretary of Defense (Health Affairs) (ASD[HA]). The DHA manages the TRICARE 
budget, executes TRICARE policies and oversees the entire TRICARE health program. (www.tricare.mil)

Active duty- persons currently serving in a branch of the armed forces in the United States. Dependent- a civilian spouse or child of an active duty member of the military. Military Treatment Facility (MTF)- The military equivalent of a civilian clinic or hospital. Active-duty personnel and family members (dependents) receive medical care and medications through the local MTF.

Temporary Duty Assignments (TDY)- military training or work away from the active duty military persons home base or where they live. The length of time for a TDY can vary from a few days to several months.

Deployment- when an active duty member is assigned to a forward conflict location for several months up to a year (can vary according to branch of service).

Rank- system of hierarchal relationships within the military. Includes commissioned officers, warrant officers, and enlisted personnel. With increasing rank comes increasing authority and responsibility. Specific insignia on uniforms denotes rank. (Roche-Paull, 2010).

Officer- personnel in the ranks of commissioned officer or warrant officer. Officers hold a position of authority granted to them by the President of the United States, charging them with the duties and responsibilities of a specific office or position. Officers generally must have a university degree. Officers receive training leadership and management training in addition to job specialty (pilot, nurse, doctor, etc.) (Roche-Paull, 2010).

Enlisted- Personnel of any rank below commissioned officer or warrant officer. Enlisted personnel perform jobs specific to their occupational specialty. 
Instillation- a military facility or base.

CONUS- Continental United States. Military instillations that are in the continuous 48 states.

Overseas/OCONUS- Overseas Continental United States- Military instillations that geographically separated from the continuous 48 states, including Alaska and Hawaii.

\section{Setting of Project}

The online survey was conducted via the online survey tool Survey Monkey. Participants could access the online survey from anywhere in the world that had computer and Internet access. Participants who met inclusion criteria and desired to complete the survey could click on the link provided via e-mail or on the Facebook page.

\section{Description of the Sample}

A convenience sample of participants were invited to take the survey if they were serving on active duty in any branch of the United States military and breastfed one or more children between 1 January 2010 and 30 September 2013. Participants were asked to fill out only one survey regardless of how many children they breastfed during this timeframe. See Figure 3 for a summary of participant inclusion and exclusion criteria.

\section{Measures (Reliability) of WBSS}

The Workplace Breastfeeding Support Scale (WBSS) is a short questionnaire to measure mothers' perceived support for breastfeeding from the workplace. The scale was originally developed to assist lactation consultants and worksite lactation program planners to help mothers returning to work and to assess the needs for improvement of support programs (Bai, Peng, \& Fly, 2008). Responses are measured on a 7-point Likert scale with a high score indicating a more 
positive perception of workplace breastfeeding support. The lowest possible score is 12 and the highest possible score is 84 . See Appendix C for the original WBSS.

The 12 questions on the scale are:

1) My co-workers agree that breastfeeding is better for baby's health than formula feeding.

2) I have supportive co-workers who cover for me when I need to pump my milk.

3) My co-workers do not make fun of me when I sometimes leak milk through my clothes.

4) Breastfeeding is common in my workplace.

5) I have a breastfeeding supportive supervisor.

6) My co-workers listen to me talk about my breastfeeding experience.

7) I feel comfortable taking several breaks during work hours to pump breast milk.

8) In my workplace, there is a designated space (nursing room) to nurse my baby or pump breast milk.

9) I can easily find a quiet place other than the bathroom at my work to pump breast milk.

10) My workplace has a refrigerator that I can use to store my milk.

11) My workplace has a breast pump for nursing mothers to use.

12) My workplace has an on-site daycare.

Participants were allowed to provide any additional comments or concerns regarding their perceptions of breastfeeding support in the military in a final, open-ended question:

"Is there anything else you would like to share about your experiences breastfeeding in the military?"

Finally, the following 10 demographic characteristics were measured using a standard questionnaire format: 
1) Age (21-29, 30-39, 40-49)

2) Ethnicity (Caucasian non-Hispanic, Hispanic, African American, Asian, other)

3) Education (high school, some college, college grad, post grad degree)

4) Socioeconomic Status (WIC eligible, WIC eligible but did not use, non-WIC eligible)

5) Rank (officer, enlisted)

6) Branch of service (Air Force, Army, Navy, Marines, Coast Guard)

7) Duty Location (Stateside (CONUS) or Overseas (OCONUS))

8) Job description (primarily administrative, non-administrative)

9) Overall, would you say you were able to meet your breastfeeding goals? (Yes, No)

10) If you were not able to meet your breastfeeding goals, what was the primary reason?

(Lack of support in the workplace, Separation from baby due to military duties, milk supply issues, baby latch issues, other, prefer not to answer)

Reliability. The items in the WBSS were derived from a literature review, then tested for internal consistency (Cronbach's alpha) and split-half reliability (r), both of which were found to be acceptable with alpha $=.77$ and $r=0.86$. Factor analyses were also done to establish reliability and construct validity of the scale. Content validity was established by review using a panel of experts. Four distinct constructs of the scale were identified that accounted for $62.1 \%$ of the total variability of the scale: technical, environmental, facility, and peer support (Bai, Peng, \& Fly, 2008).

\section{Procedures}

Beginning 1 February 2014, the direct link to the Survey Monkey self administered survey was posted on a Facebook page entitled "Breastfeeding Support for Active Duty Mothers" 
and e-mailed to local breastfeeding support group leaders. See Appendix D to see the survey invitation sent via e-mail and embedded on the Facebook page. The target population was women who were on active duty in any branch of the military, any rank, and breastfed at least one child anytime from 1 January 2010 to 30 September 2013. Local breastfeeding support groups in the Hampton Roads area of Virginia such as the La Leche League (LLLI) and IBCLCs that provide breastfeeding support to active duty women in the area were e-mailed with a link to the survey and Facebook page to pass along to active duty members that met inclusion criteria. Support group leaders and Lactation Consultants were instructed that passing along the survey information was voluntary. Participants could voluntarily access the survey either by clicking on the direct link to the Survey Monkey survey or by going to the Facebook page first, then clicking on the Survey Monkey link. See Appendix E for a copy of the Survey Monkey permission to conduct research letter.

The survey invitation and consent page provided a brief description of the survey contents, the aims and goals of the capstone, and contact information for the primary researcher and UVA academic advisor. A statement that the capstone project and survey were being done to meet requirements for a doctoral program through UVA and not sponsored by the DoD or Air Force was also included in the consent. See Appendix F for the modified WBSS survey including the consent page.

After a period of one month the survey was closed and an announcement was sent to local breastfeeding support group leaders and placed on the Facebook page that you could no longer participate in the survey. Appreciation was expressed for everyone who participated in 
addition to information regarding announcement of results and manuscript publication in June 2014. The survey close announcement can be seen in Appendix G.

\section{Protection of Human Subjects}

The University of Virginia Institutional Review Board for Social and Behavioral Sciences (IRB-SBS) was consulted and the project was considered exempt from IRB-SBS review. See Appendix H for a copy of the IRB-SBS exemption letter. The survey invitation and consent stated that participation was voluntary and this capstone project was not affiliated with the Department of Defense or any military branch. The consent page further disclosed that no personal identifiable information would be collected in the survey and all responses would be kept anonymous. No compensation was offered and participants were informed that they could exit the survey at any time as well as withdraw at the end of the survey if they did not want their responses collected. For each demographic question in the survey, participants were given the option "prefer not to answer". Participants were further assured that there would be no efforts made to identify or contact them and there would be no retaliation or negative consequences for declining to participate or withdrawing from the survey.

\section{Results}

\section{Sample}

The sample consisted of a total of 318 respondents to the online survey from the five branches of the U.S. military (Army, Air Force, Navy, Marine Corps, Coast Guard). The demographic characteristics of the 318 subjects are shown in Table 4 . The majority of active duty military all-female participants were in the $21-29$ year age range $(n=164 ; 51.6 \%)$. Over $75 \%$ of participants were Caucasian $(n=254)$, followed by Hispanic non-white $(n=38 ; 12 \%)$, 
and Other- non-Hispanic $(n=20 ; 6 \%)$. While a majority had completed some college ( $n=113$; $36 \%)$ or were college graduates $(n=107 ; 34 \%)$, some had post graduate degrees $(n=78 ; 24 \%)$. A vast majority did not meet low-income eligibility for WIC assistance ( $n=256 ; 81 \%)$. A higher percentage of participants held enlisted rank $(n=182 ; 57 \%)$ than officer rank $(n=132 ; 42 \%)$. There were participants from each branch of service with the majority in the Air Force ( $n=120$; $38 \%)$ and Army $(n=116 ; 37 \%)$ followed by Navy $(n=51 ; 16 \%)$, Marines $(n=18 ; 6 \%)$, and Coast Guard $(n=13 ; 4 \%)$. A majority of participants were stationed stateside $(n=260 ; 82 \%)$ and many had primarily administrative duties ( $n=174 ; 55 \%)$ while breastfeeding. Overall, a majority of participants stated that they were able to meet their breastfeeding goals ( $n=205 ; 65 \%)$. Those that stated that they were not able to meet their breastfeeding goals $(n=107 ; 34 \%)$ selected lack of support in the workplace being the primary reason $(n=45 ; 14 \%)$ followed closely by milk supply issues $(n=43 ; 13.5 \%)$ and separation from baby due to military duties (deployments, Temporary Duty Assignments (TDYs), training exercises, etc.) $(n=40 ; 12.6 \%)$.

Chi-square tests for differences in proportions revealed that there were some statistically significant differences in demographic characteristics of the sample participants depending on different branches (Army, Air Force, Navy/Marines) and between the two ranks (Enlisted vs. Officer). See Table 5 for a comparison of the demographic characteristics of participants by rank and Table 6 for a comparison of participant demographics by branch of service. For example, the proportion of White, Non-Hispanic was much lower in the Army (67.8\%) than in the Air Force (82.1\%) and the Navy/Marines (80.9\%). Also the proportion of those with only a High School or some college education was much higher in the Navy/Marines (56.5\%) than in the Air Force (35.3\%) and in the Army (37.9\%). While there was no difference in ethnicity by rank, enlisted 
participants were more likely to be under age 30 , have achieved less education, and were more likely to be WIC eligible.

\section{WBSS Scores and Selected Demographic Variables}

The Workplace Breastfeeding Support Scale (WBSS), scores ranged from 12 to 84 with higher scores indicating a higher perception of breastfeeding support in the workplace. The overall average WBSS score in this sample was $50.20(S D=15.75)$. The WBSS was tested for reliability in this sample with a Cronbach's alpha of 0.85 , indicating good internal consistency reliability (Nunnally \& Bernstein, 1994).

Differences among WBSS scores were evaluated using one-way ANOVA for particular demographic groups. Among the three level ethnic/race groups (Hispanic, White- Non-Hispanic, Other- non-Hispanic) WBSS scores differed significantly across the three groups, $F(2,287)=$ $3.67, p=.027$. Bonferonni post-hoc comparisons of the three groups indicated that the Hispanic group $(M=44.30,95 \%$ CI $[38.50,50.09])$ had significantly lower WBSS scores than the White, non-Hispanic group $(M=50.80,95 \% \mathrm{CI}[48.77,52.84])$ and the Other- non-Hispanic group $(M=$ 53.81, 95\% CI [48.64,58.97]). Both of the non-Hispanic groups (White and Other) did not significantly differ from each other in WBSS scores at $p<.05$.

WBSS differences among three groups differentiated by education level (High School/Some College, College Graduate, Graduate Degree) were also calculated using one-way ANOVA. WBSS scores differed significantly across the three groups, $F(2,291)=5.148, p$ $=.006$. Bonferonni post-hoc comparisons of the three groups indicated that the High School/Some College group $(M=46.90,95 \%$ CI $[43.99,49.81])$ had significantly lower WBSS scores than the group with Graduate Degrees $(M=53.94,95 \%$ CI $[50.41,57.48])$, but did not 
significantly differ from the group of College Graduates $(M=51.45,95 \%$ CI $[48.45,54.45])$.

The WBSS scores of College Graduates and those with Graduate Degrees did not significantly differ at $p<.05$.

\section{WBSS Scores and Military Service}

Before conducting a 2-way ANOVA of WBSS scores depending on branch of service and rank, the item assessing military branch was re-coded to reflect three groups (Army, Air Force, and Navy/Marines), so that adequate group size was present. The few respondents who were part of the Coast Guard $(n=13)$ were treated as missing in the analysis because their group size was too small for meaningful comparison. Navy and Marines were combined because they are considered "sister services" that have similar policies and command structure. A consort diagram summarizing the loss of sample size for the two-way ANOVA can be seen in Figure 4. The univariate and multivariate distribution of the WBSS scores by participant rank and military branch were assessed as normal with no outliers. There was homogeneity of variances, as assessed by Levene's Test of Homogeneity of Variance $(p=.61)$. See Table 7 and Figure 5 for the estimated marginal means of WBSS by rank and branch.

The results of the 2-way ANOVA indicated that there was no significant interaction effect of rank by branch $\left(F(2,275)=.902, p=.407\right.$, partial $\left.\eta^{2}=.007\right)$. There was, however, a statistically significant difference in mean WBSS scores depending on rank (officers vs. enlisted), $F(1,277)=15.67, p<.001$, partial $\eta^{2}=.05$. Officers had higher WBSS scores $(M=54.62)$ than enlisted $(M=47.12)$. There was also a statistically significant difference in mean WBSS scores depending on branch of service (Air Force, Army, Navy/Marines), $F(2,277)=8.37, \mathrm{p}<.001$, partial $\eta^{2}=.06$. While the mean WBSS scores did not differ significantly between the Air Force 
and the Navy/Marines $(M=52.80)$ nor between the Army and the Navy/Marines, the mean WBSS score of the Army $(M=45.85)$ was significantly lower than the Air Force mean WBSS

score $(M=53.96, p<.001)$. The effect sizes $\left(\eta^{2}\right)$ reflect a medium magnitude of the effect of rank and branch in explaining variability of WBSS scores in this sample.

Officers and enlisted personnel in the Air Force had the highest perception of workplace breastfeeding support with average scores of 58.9 (officer) and 49.0 (enlisted). The Navy \& Marines had slightly lower perceptions of workplace breastfeeding support scoring 56.9 (officers) and 48.7 (enlisted). Army officer and enlisted personnel had the lowest perception of workplace breastfeeding support scoring 48.1 (officer) and 43.6 (enlisted) on the WBSS. Overall, the officers averaged a 7.5-point higher WBSS score than enlisted.

A comparison of scores per WBSS question and each branch of service was evaluated. The WBSS question that had the highest average score for perception of workplace breastfeeding support was "My workplace has a refrigerator that I can use to store my milk" (5.41) followed by "My co-workers agree that breastfeeding is better for baby's health than formula feeding" (5.20). The WBSS question, "My workplace has a breast pump for nursing mothers to use" had the lowest average score (1.79). See Table 8 and Figure 6 for an overall comparison of WBSS scores per question according to branch of service.

\section{Qualitative Analysis}

At the end of the survey, one open-ended item was included: "Is there anything else you would like to share about your experiences breastfeeding in the military?" Over 190 participants responded. While this data was not formally analyzed, common themes were identified using Survey Monkey Text Analysis software. The four primary keywords identified 
were "months" ( $n=43 ; 21.61 \%)$, "nursing" $(n=41 ; 20.60)$, "room" $(n=37 ; 18.59 \%)$, and "baby" $(n=35 ; 17.59 \%)$. These keywords were used to identify common themes that expressed positive and/or negative support for breastfeeding in the military setting. Lactation policy implementation, duty requirements, and lack of support were three common themes identified.

Lactation policy implementation. The lack of consistency in lactation policy implementation and adherence at military facilities was a common barrier discussed by many participants:

The Pentagon was actually the most supportive place that I found because they actually have designated nursing rooms with pumps and fridges and everything. Andrews AFB and Peterson AFB have not been so friendly, and I usually just have to find an empty office. All of my supervisors have been supportive...

In spite of policies in place that require nursing mothers have a time and a place to pump, a majority of respondents stated that the lack of time and space for pumping was the primary obstacle. According to one active duty mother, "The hardest thing that I have encountered is actually finding a place beside a bathroom or hiding in my car to pump".

Duty requirements. Many respondents discussed duty and travel requirements that made it difficult to meet their breastfeeding goals:

I am a helicopter pilot and found that although my command was extremely supportive in every way that they could be, it did not make it any easier to have to pump while out on long flights. I could not pump in the aircraft, but if my flight did not terminate at home base, I had to run into the bathroom and pump while my crew took care of fueling the aircraft and flight planning. That was fine as I was in the role of the co-pilot at the time, 
with my 2nd on the way, I feel nervous about it because I am the aircraft commander and need to be the one doing the flight planning etc, not stuck in the bathroom, even if my crew understands, it presents a challenge. If I get stuck somewhere overnight, then I have the challenge of preserving the milk and getting it home safely, which I might not have the services for depending on where we land.

Support. Lactation support from co-workers, supervisors, and the military community had a large influence on respondents meeting their breastfeeding goals. Many women felt pressure from co-workers to stop taking breaks to pump:

While nursing, some co-workers would complain that I had to pump. They felt that I was nursing to get out of work. At times, finding a room to nurse in was not easy-I had to wait for a room to open up; also, there were times I would have to pump later than I should have because I was busy and felt like I had to pick up more slack because I was going to pump. We have [Air Force Instructions] (AFIs) to support nursing; however, education for everyone and the support given could be improved for those of us who do nurse.

Some respondents stated they felt pressured by co-workers to switch to formula to reduce the number of pumping breaks:

Although [Air Force Instruction] states we are authorized two 15-minute breaks per day, it is not enough time. Many times I ended up pumping in the bathroom, being rushed the whole time due to manning constraints and then being looked down on as not being as hard a worker as everyone else because of these breaks. Also, in my facility, we do not receive lunch breaks to be able to get a third pumping session in. No leeway was granted 
me, I was treated poorly and given complete disrespect over my choice to pump instead of just giving formula.

Despite many obstacles experienced by active duty women regarding workplace lactation support, approximately half of the respondents described positive breastfeeding experiences and support from co-workers or supervisors in military settings:

So far I've been fortunate to have a wonderful experience. My command team has been very supportive and flexible with me pumping and breastfeeding. They've allowed for me to have assistance when pumping during an FTX, breastfeed in uniform on multiple occasions, and allow me to educate the other pregnant soldiers in the unit on breastfeeding and working. Though there was no designated pumping room and I was walked in on/forced to pump in the restroom many times I still feel very fortunate that I was able to make it to my first goal. $(13+$ months now!)

\section{Discussion}

The results of the online survey showed that current perceptions of breastfeeding support among active duty women are divided between positive and negative perceptions. Compared to previous studies, since the majority of active duty mothers reported they were able to meet their breastfeeding goals, the results also indicated favorable breastfeeding support in military settings. Participant responses did, however, identify multiple barriers to breastfeeding support that persist despite lactation policy implementation throughout the DoD. Figure 7 summarizes the demographic characteristics of active duty women with significantly lower perceptions of breastfeeding support in military settings per the WBSS survey. 


\section{Perceptions of Breastfeeding Support and Demographics}

A Morbidity and Mortality Weekly Report (MMWR) published by the Center for Disease Control and Prevention (CDC) discusses the many factors that influence breastfeeding initiation and duration including race/ethnicity, education, age, and income (2013). Minorities, younger age, less maternal education, and lower income levels are all characteristics associated with lower breastfeeding prevalence (Grummer \& Shealy, 2009). Similarly, the active duty women who participated in this capstone who are Hispanic, less than 30 years of age, have lower education levels, and lower income had lower perceptions of breastfeeding support.

Race/Ethnicity. Hispanic active duty women who participated in this survey had significantly lower perceptions of breastfeeding support than White, non-Hispanic participants. Comparisons with African Americans were not possible due to low AA participation $(n=20$; 6.3\%). It's possible that the low AA active duty participation rate is somewhat a reflection of the low prevalence of AA breastfeeding in the general population. The National Immunization Survey (NIS) reported that for births between 2000 and 2008, breastfeeding for AA infants fell significantly below white, non-Hispanic and Hispanic breastfeeding rates (2012).

According to the MMWR report on ethnic disparities in breastfeeding rates (CDC, 2013), the persistent gap in breastfeeding rates among AA women and other ethnic and racial groups in the U.S. might be an indication of unsupportive cultural norms, perceptions that breastfeeding is inferior to formula, a lack of partner support, or unsupportive work environments. Further investigation into the ethnic differences in breastfeeding rates and 
the perceptions of breastfeeding support should be done in military settings so the educational and support needs of all active duty women can be met.

Rank. The association of rank with perceptions of breastfeeding support likely reflects the demographic characteristics of military members. Military officers have higher levels of education, higher income levels, and are older ( $>30)$ than enlisted members on average (Office of the Deputy Assistant Secretary of Defense, 2012). Officers, in general, have more autonomy and control over their work environment. Therefore, it was not surprising that active duty mothers who are officers had significantly higher perceptions of breastfeeding support than enlisted mothers in all branches of service. In addition, active duty mothers with graduate degrees had significantly higher perceptions of breastfeeding support than active duty mothers with lower levels of education (i.e. high school diploma and/or some college). These findings indicate that specific attention to the breastfeeding support needs of enlisted women should be emphasized in policy implementation throughout the DoD.

\section{Service Disparities}

Air Force women (officer and enlisted) had the highest perceptions of breastfeeding support followed by women in the Navy and Marines. Active duty women in the Army had the lowest perceptions of breastfeeding support. The lack of a formal lactation policy for Army soldiers is a possible contributor to the low WBSS scores. The findings could be used to increase awareness of the need for a formal lactation policy in the Army. In addition, the demographic characteristics of participants in each branch of service could also be indicative of WBSS scores. For example, the Army had the highest proportion of participants that were Hispanic $(n=22 ; 19.1 \%)$. Since being Hispanic was associated with lower WBSS scores, it's 
possible that some of the variation in WBSS scores for the Army participants was explained by race/ethnicity and not by branch of the military.

The Air Force had the highest proportion of participants that were White, NonHispanic $(n=96 ; 82.1 \%)$ and had either a college degree $(n=42 ; 35.3 \%)$ or a graduate degree $(n=$ $35 ; 29.4 \%)$. It's likely that higher WBSS scores in the Air Force is somewhat related to the higher proportion of White, Non-Hispanics and more highly educated participants. While it is difficult to parse out the effects of race/ethnicity and education from the effects of military branch on WBSS scores, it is clear that the breastfeeding support within the Army could be improved.

A study examining the association between the different dimensions of breastfeeding support and the duration of exclusive breastfeeding was recently done by Bai \& Wunderlich, 2013). The researchers used a survey that was adopted and modified from previously used questionnaires, including the WBSS (Bai \& Wunderlich, 2013). This study found that technical support (availability of breast pumps and a place to store milk, $r=0.71, p=.01$ ) and workplace environment (social support by peers and supervisors, $r=0.26, p=.01$ ) showed significant positive correlations with the duration of breastfeeding. These results emphasize the importance of the WBSS and the capstone survey for assessing the perception of breastfeeding support for active duty women and the implications for breastfeeding duration in this population.

Comparisons can be made for specific WBSS questions between the more recent Bai \& Wunderlich study (2013) of civilian women and the scores from the active duty participants in this capstone. For the WBSS question "I have supportive co-workers who cover for me when I need to pump my milk", participant's average response was 5.40 (SD 1.37) in the Bai study. For 
active duty mothers, average scores were slightly lower with the Army having the biggest difference with an average score of 4.55. For the WBSS question, "I can easily find a quiet place other than the bathroom at my work to pump breast milk", the average response in the Bai study was 4.62 (2.16). For the same question, active duty mothers in the Air Force (4.69), Navy (4.68), and Coast Guard (5.62) scored higher compared to Army and Marines who only had average scores of 3.93 and 2.56 , respectively.

WBSS score comparisons for co-worker support suggests a need for education on the importance of breastfeeding and lactation accommodation in the workplace for all members of the military, not just active duty mothers. The Coast Guard has the highest scores related to workplace lactation accommodations such as time and place to pump. Other military branches may want to implement and enforce lactation policies similar to the Coast Guard to improve perceptions of breastfeeding support. An official lactation policy in the Army accompanied by supervisor breastfeeding education could help improve support for soldiers.

Social and cultural acceptance of breastfeeding in military settings will improve as accommodations and policies for active duty breastfeeding mothers are standardized and enforced throughout the DoD. Breastfeeding support policies should be promoted and enforced in military settings similar to other healthy behaviors such as diet and exercise to ensure the health and well-being of sailors, soldiers, airmen and marines and their families. TRICARE coverage of breast pumps and supplies for all military beneficiaries would help provide breastfeeding support for all military beneficiaries similar to the PPACA and coverage for the general population. Finally, hospital grade breast pumps and supplies could be made available in DoD facilities that have a significant number of active duty females. 


\section{Strengths of the Capstone}

The use of social media to disseminate the online survey proved to be a cost efficient and effective data collection tool to meet the aims of this capstone. A large sample size of active duty women with varied demographic characteristics was collected for statistically and clinically relevant comparisons and recommendations. All branches of the military are represented with equal numbers of officers and enlisted members.

Previous studies evaluating breastfeeding policies and support programs in military settings have been limited by the low numbers of active duty participants, the small number of military installations evaluated, or the focus on one particular branch of service. The online survey method enabled accessibility for women in all branches of the military at various installations around the world. This increased the generalizability of the results across military ranks and services.

The brevity and convenience of the online survey aimed to encourage participation and serve as a foundation to guide future research. The combination of demographic questions and the WBSS used in this survey provide valuable data that can be easily replicated and used for ongoing evaluation of breastfeeding support for active duty women.

\section{Weaknesses of the Capstone}

A limitation for result validation and generalizability is the convenience sampling data collection method used. The lack of random selection possibly excluded groups of active duty women with either positive or negative perceptions of breastfeeding support.

Ethnic comparisons for perceptions of breastfeeding support are limited due to the lack of participant diversity. The vast majority of white, non-Hispanic participants and conversely the 
small number of AA participants minimize practice implications and generalizability of results. Future studies should focus attention on obtaining more diverse representation from all ethnic groups of active duty mothers.

There are many complex factors that can affect a woman's breastfeeding success. The 12-question WBSS does not provide a comprehensive evaluation of all factors that can affect the perceptions of breastfeeding support. For example, the amount of lactation support provided by military healthcare workers, family separation influences on lactation, and social norms in military settings could have direct and indirect influences on lactation practices for active duty women that are not fully assessed by the WBSS and warrant further investigation. In addition, the retrospective, cross- sectional survey does not account for WBSS score variations over time. Therefore, the survey could be administered to active duty mothers at different stages of breastfeeding to identify where support is needed most.

\section{Nursing Practice Implications}

Military nurses are in key positions to promote and support lactation programs as well as provide education on the importance of breastfeeding from patients to policy makers. This capstone shows that active duty military mothers who are enlisted rank, Hispanic ethnicity, have lower education levels, and in the Army have lower perceptions of breastfeeding support. Nurses in military settings can improve perceptions of breastfeeding support in these particular demographics by focusing efforts to improve workplace support programs designed to target these populations. The following list of nursing strategies to support breastfeeding women was adapted from breastfeeding support implementation strategies set forth by The Surgeon General's Call to Action to Support Breastfeeding (2011) and recommendations from a study 
entitled Lactation Accommodation in the Workplace and Duration of Exclusive Breastfeeding (Bai \& Wunderlich, 2013):

- Ensure training on the use of breast pumps and milk storage is incorporated into breastfeeding education classes on military instillations for women who will be returning to work after maternity leave; ensure ongoing support and follow-up classes.

- Develop resources to help commanders and supervisors comply with current military breastfeeding policies.

- Design and disseminate materials to educate commanders and supervisors about the benefits of providing more comprehensive, high-quality support for breastfeeding active duty mothers.

- Identify individual obstacles to successful breastfeeding (duty requirements, separations from baby, lack of co-worker support) and develop a plan of action to overcome obstacles and meet breastfeeding goals (i.e. income, ethnicity, age).

- Work with instillation and unit commanders to promote comprehensive, high-quality lactation support programs at each military installation that includes IBCLCs.

- Educate active duty mothers, supervisors, and commanders on current federal laws and military policies regarding lactation.

- Promote and advocate policies that support breastfeeding mothers in the military such as a military-wide comprehensive breastfeeding policy.

- Political involvement recommending TRICARE to amend current policies that provide reimbursement for breast pumps which are consistent with civilian insurance policies under the PPACA (2010). 
The WBSS was originally constructed to assist lactation consultants and worksite lactation program planners improve breastfeeding education and support programs. Nurses and midwives in military settings can do the same by assessing the perceived breastfeeding support of active duty mothers and identifying areas for improvement. By identifying gaps in breastfeeding support in the military, nurses and others can focus their efforts on developing or improving existing programs and policies that will assist active duty mothers in meeting their breastfeeding goals.

\section{Implications for Future Research}

The gaps in perceived breastfeeding support found in this capstone should be used as a starting point for ongoing development, implementation, and evaluation of policies and programs that promote breastfeeding for all active duty mothers. In order to optimize lactation support and thus breastfeeding rates throughout the $\mathrm{DoD}$, the following targeted areas should be evaluated in the future:

- Explore the association between prevalence of breastfeeding and perceptions of breastfeeding support in the active duty population.

- Identify specific socioeconomic factors that influence breastfeeding initiation and duration in active duty mothers.

- Explore internal and external factors that affect breastfeeding duration in the active duty population.

- Investigate ethnic disparities in breastfeeding rates specifically in the active duty population. 
- Develop, implement, and evaluate breastfeeding support programs with a focus on enlisted and minority active duty women throughout the DoD.

\section{Products of the Capstone}

The products of this capstone project include: (1) evaluation of current perceptions of breastfeeding support among active duty military mothers (2) comparison of current military breastfeeding policies; (3) policy implications for breastfeeding support in military settings; (4) implications for military nursing practice and education to promote breastfeeding among active duty mothers; (5) implications for future research on lactation support for active duty mothers; (6) and a manuscript submission to Military Medicine (Appendix I). 


\section{References}

Air Force Instruction (AFI) 44-102. Section 4.16: Breastfeeding and Breast Pumping (2006, revised Jan 2012). Medical Care Management by order of the Secretary of the Air Force.

Army Regulation (AR) 40-501 (2007). Standards of Medical Fitness, Pregnancy and Postpartum Profiles.

American Academy of Family Physicians (AAFP) (2014). Family Physicians Supporting Breastfeeding: Position Paper. Retrieved from http://www.aafp.org/about/policies/all/breastfeeding-support.html

Baby-Friendly USA, (2010). The ten steps to successful breastfeeding (MCHB 03-0232P). East Sandwich, MA: Baby-Friendly USA.

Bai, Y., Peng, J., \& Fly, A. (2008). Validation of a short questionnaire to assess mother's perception of workplace breastfeeding support. Journal of the American Dietetic Association, 108(7), 1221-25.

Bai, Y., \& Wunderlich, S. (2013). Lactation Accommodation in the Workplace and Duration of Exclusive Breastfeeding. Journal of Midwifery \& Women's Health, 58(6), 690-96.

Bales, K., Washburn, J., \& Bales, J. (2012). Breastfeeding rates and factors related to cessation in a military population. Breastfeeding Medicine, 7(6), 436.

Bar-Yam, N.B. (2004). Nursing Mothers at Work: Corporate and Maternal Strategies to Support Lactation in the Workplace. Journal of the Association for Research on Mothering, 6(2), $127-138$. 
Bartick, M., \& Reinhold, A. (2010). The burden of suboptimal breastfeeding in the United States: A pediatric cost analysis. Pediatrics, 125(5), 1048-56. doi: 10.1542/peds.20091616

Bell, M., \& Ritchie, E. (2003). Breastfeeding in the military: Part 1, information and resources provided to service women. Military Medicine, 168(10), 807.

Bell, M., \& Ritchie, E. (2003). Breastfeeding in the military: part II, resource and policy considerations. Military Medicine, 168(10), 813.

Bettinelli, M. E. (2012). Breastfeeding policies and breastfeeding support programs in the mother's workplace. The Journal of Maternal-Fetal and Neonatal Medicine, 25(54), 8182.

Binns, C., James, J., \& Lee, M. (2013). Breastfeeding and the developing brain. Breastfeeding Review, 21(2), 11-13.

Bonuck, K. A., Trombley, M., Freeman, K., \& McKee, D. (2005). Randomized, controlled trial of a prenatal and postnatal lactation consultant intervention on duration and intensity of breastfeeding up to 12 months. Pediatrics, 116(6), 1413-26. doi: doi: 10.1542/peds.20050435

Buckler, A.G. (2011). The Military Health System and TRICARE: Breastfeeding Promotion. Breastfeeding Medicine, 6(5), 295-297. doi: 10.1089/bfm.2011.0065

Centers for Disease Control and Prevention (February 8, 2013). Progress in Increasing Breastfeeding and Racial/Ethnic Differences- United States, 2000-2008 Births. MMWR, $62(5), 77-80$. 
Coast Guard Commandant Instruction 1000.9: Pregnancy in the Coast Guard. 29 September, 2011.

Department of Defense Report to the White House Council on Women and Girls (1 September 2009).

Department of Defense Instruction (DoDI) Number 1010.10. (28 April 2014). Health Promotion and Disease Prevention.

DiGirolamo, A., Grummer-Strawn, L., \& Fein, S. (2003). Do perceived attitudes of physicians and hospital staff affect breastfeeding decisions?. Birth, 30, 94-100.

Eidelman, A., \& Schanler, R. (2012). Breastfeeding and the use of human milk. Pediatrics, 129(3), 827-841. doi: 10.1542/peds.2011-3552

Feldman-Winter, L. (2013). Evidence-based interventions to support breastfeeding. Pediatric Clinics of North America, 60, 169-187.

George, J. (2010). Nursing theories: The base for professional nursing practice. (6th ed.). Upper Saddle River, NJ: Prentice Hall.

Haas, D., Howard, C., Christopher, M., Rowan, K., Broga, M., \& Corey, T. (2006). Assessment of breastfeeding practices and reasons for success in a military community hospital. Journal of Human Lactation, 22(4), 439-445.

IP, S., Chung, M., Raman, G., Chew, P., Magula, N., DeVine, D., Trikalinos, T., \& Lau, J. Agency for Healthcare Research and Quality, U.S. Department of Health and Human Services. (2007). Breastfeeding and maternal and infant health outcomes in developed countries (Evidence Report/Technology Assessment No. 153). Retrieved from AHRQ Publication No. 07-E007 website: www.ahrq.gov 
Marine Corps Order (MCO) 5000.12E Section 15.8 MARADMIN 358/07 (December 2004).

Mills, S. P. (2009). Workplace lactation programs: A critical element for breastfeeding mothers' success. American Association of Occupational Health Nurses Journal, 57(6), 227-31.

Moore, E., \& Anderson, G. (2007). Randomized controlled trial of very early mother-infant skinto-skin contact and breastfeeding status. Journal of Midwifery \& Women's Health, 52(2), 116-125.

Murtagh, L., \& Moulton, A. (2011). Strategies to Protect Vulnerable Populations: Working Mothers, Breastfeeding, and the Law. American Journal of Public Health, 101(2), 217223. doi: 10.2105/AJPH.2009.185280

National Center for Chronic Disease Prevention and Health Promotion, Division of Nutrition, Physical Activity, and Obesity. (2013). Breastfeeding report card- United States. Retrieved from Centers for Disease Control and Prevention website: $\underline{w w w . a t s d r . c d c . g o v}$ National Center for Veterans Analysis and Statistics (November 2011). America's Women Veterans: Military Service History and VA Benefit Utilization Statistics. National Center for Veterans Analysis and Statistics, Department of Veterans Affairs, Washington, DC. Navy Instruction (OPNAVINST) 6000.1c. and BUMEDINST 6000.14 (14 June 2007). Navy Guidelines Concerning Pregnancy and Parenthood.

Nunnally, J. C., \& Bernstein, I. H. (1994). Psychometric Theory (3rd edition.). New York, NY: McGraw-Hill.

Roche-Paull, R. (2010). Breastfeeding in combat boots: A survival guide to successful breastfeeding while serving in the military. Amarillo: Hale Publishing, L.P. 
Rishel, P., \& Sweeney, P. (2005). Comparison of breastfeeding rates among women delivering infants in military treatment facilities with and without lactation consultants. Military Medicine, 170(5), 435.

Stevens, K., \& Janke, J. (2003). Breastfeeding experiences of active duty military women. Military Medicine, 168(5), 380.

Thulier, D. (2009). Breastfeeding in America: A history of influencing factors. Journal of Human Lactation, 25(1), 85-94. doi: 10.1177/0890334408324452

TRICARE Policy Manual 6010.57-M (1 February 2008). Breast Pumps. Authority: 32 CFR $199.4(d)(1)$

United States Breastfeeding Committee, (2010). Workplace accommodations to support and protect breastfeeding. Washington, D.C.: United States Breastfeeding Committee.

Uriell, Z., Perry, A., Kee, A., \& Burress, L. (2009). Breastfeeding in the Navy: Estimates of Rate, Duration, and Perceived Support. Military Medicine, 174(3), 290-296.

U.S. Department of Health and Human Services, (2010). Healthy People 2020. Retrieved from website: http://www.healthypeople.gov/2020/about/default.aspx

U.S. Department of Health and Human Services (2008). Health Resources and Services Administration (HRSA). The business case for breastfeeding: Employees' guide to breastfeeding and working. Retrieved from U.S. Department of Health and Human Services website: www.mchb.hrsa.gov/pregnancyandbeyond

U.S. Department of Health and Human Services, Office of the Surgeon General. (2011). The surgeon general's call to action to support breastfeeding. Retrieved from U.S. Department of Health and Human Services website: http://www.surgeongeneral.gov 
U.S. Department of Labor: Wage and Hour Division. (August 2013). Fact Sheet \#73: Break Time For Nursing Mothers Under the Fair Labor Standards Act (FLSA)

Wolf, J. (2003). Low Breastfeeding Rates and Public Health in the United States. American Journal of Public Health, 93(12), 2000-2010.

Ziobro, M. (2010). Historical Perspective: Pregnancy in the Military. Monmouth Message. 


\section{Appendix A}

\section{Review of Literature}

\begin{tabular}{|c|c|c|c|c|c|}
\hline Author & $\begin{array}{l}\text { Subject and } \\
\text { Setting }\end{array}$ & $\begin{array}{l}\text { Design/Level of } \\
\text { Evidence }\end{array}$ & $\begin{array}{c}\text { Intervention } \\
\text { and } \\
\text { Comparison }\end{array}$ & Outcomes & $\begin{array}{l}\text { Study } \\
\text { Limitations }\end{array}$ \\
\hline $\begin{array}{l}\text { 1) Bell, } \\
\text { M.R., \& } \\
\text { Ritchie, E.C. } \\
\text { (2003) }\end{array}$ & $\begin{array}{c}\text { Evaluation } \\
\text { included one- } \\
\text { third of } \\
\text { Department of } \\
\text { Defense (DoD) } \\
\text { hospitals that } \\
\text { provided } \\
\text { obstetric care. }\end{array}$ & $\begin{array}{l}\text { Evaluation of DoD and } \\
\text { TRICARE breastfeeding } \\
\text { support policies and } \\
\text { programs. } \\
\text { Literature review and } \\
\text { telephone surveys } \\
\text { conducted. } \\
\text { Level VII }\end{array}$ & None & $\begin{array}{l}\text { - DoD facility } \\
\text { lactation support } \\
\text { programs } \\
\text { inconsistent. } \\
\text { - Minimal DoD } \\
\text { lactation policy } \\
\text { guidance. } \\
\text { - Need for more } \\
\text { standardized } \\
\text { breastfeeding } \\
\text { support programs } \\
\text { in place such as } \\
\text { lactation } \\
\text { consultants and } \\
\text { educational } \\
\text { materials/classes } \\
\text { both inside and } \\
\text { outside the } \\
\text { hospital. } \\
\text { - Active duty } \\
\text { mothers had } \\
\text { substantially less } \\
\text { breastfeeding } \\
\text { support than } \\
\text { civilian mothers } \\
\text { with only } 47 \% \text { of } \\
\text { military hospital } \\
\text { surveyed } \\
\text { providing support } \\
\text { services for } \\
\text { working mothers. }\end{array}$ & $\begin{array}{l}\text { Limited number of } \\
\text { DoD wide } \\
\text { facilities/hospitals } \\
\text { surveyed. } \\
\text { Possibly only } \\
\text { hospitals that } \\
\text { agreed to survey } \\
\text { were ones that } \\
\text { had strong } \\
\text { lactation support } \\
\text { programs in place. }\end{array}$ \\
\hline $\begin{array}{c}\text { 2) Bell, } \\
\text { M.R., \& } \\
\text { Ritchie, E.C. } \\
\text { (2003) }\end{array}$ & $\begin{array}{l}\text { Policy guidance } \\
\text { and } \\
\text { recommendations } \\
\text { to support active } \\
\text { duty women who } \\
\text { desire to } \\
\text { breastfeed after } \\
\text { returning to work. }\end{array}$ & $\begin{array}{l}\text { Literature and policy } \\
\text { review of DoD } \\
\text { breastfeeding and } \\
\text { lactation support. } \\
\text { Recommendations and } \\
\text { policy guidance given to } \\
\text { improve breastfeeding } \\
\text { rates among active duty } \\
\text { women. } \\
\text { Level VII }\end{array}$ & None & $\begin{array}{l}\text { Tricare and DoD } \\
\text { not meeting HP } \\
2010 \text { goals of } \\
\text { lactation support. } \\
\text { Recommendations } \\
\text { for DoD: } \\
\text { *standardize } \\
\text { hospital lactation } \\
\text { education and } \\
\text { explanation of }\end{array}$ & $\begin{array}{c}\text { No specific } \\
\text { guidance given on } \\
\text { how to meet HP } \\
2010 \text { goals or how } \\
\text { to accomplish } \\
\text { recommendations. }\end{array}$ \\
\hline
\end{tabular}




\begin{tabular}{|c|c|c|c|c|c|}
\hline & & & & $\begin{array}{l}\text { TRICARE coverage } \\
\text { *Improve } \\
\text { workplace support } \\
\text { and minimize } \\
\text { exposure to } \\
\text { harmful chemicals } \\
\text { *Improve } \\
\text { community social } \\
\text { support and } \\
\text { information } \\
\text { resources }\end{array}$ & \\
\hline $\begin{array}{l}\text { 3) Bales, K., } \\
\text { Washburn, } \\
\text { \& Bales, J. } \\
\text { (2012) }\end{array}$ & $\begin{array}{l}\text { Telephone survey } \\
\text { of active duty and } \\
\text { dependent } \\
\text { women at a } \\
\text { regional military } \\
\text { medical facility } \\
\text { regarding their } \\
\text { ability to } \\
\text { successfully } \\
\text { breastfeed. } \\
\mathrm{N}=254\end{array}$ & $\begin{array}{c}\text { Mixed } \\
\text { Qualitative/Quantitative } \\
\text { data. } \\
\text { A prospective } \\
\text { correlational survey. } \\
\text { Level VI }\end{array}$ & none & $\begin{array}{l}\text { - Comparison of } \\
\text { AD vs non AD } \\
\text { showing } 37.9 \% \text { of } \\
\text { non AD able to } \\
\text { meet BF goals } \\
\text { compared to } 31 \% \\
\text { of AD mothers. } \\
\text { - More studies } \\
\text { needed pertaining } \\
\text { to AD mothers. } \\
\text { - AD mothers fell } \\
\text { significantly short } \\
\text { of HP } 2010 \text { BF } \\
\text { goals and may } \\
\text { need additional } \\
\text { support after } \\
\text { returning to work } \\
\text { to help meet their } \\
\text { BF goals. }\end{array}$ & $\begin{array}{l}\text { Survey conducted } \\
\text { at only one } \\
\text { military treatment } \\
\text { facility with } \\
\text { majority of Air } \\
\text { Force personnel, } \\
\text { minimal } \\
\text { generalizability. }\end{array}$ \\
\hline
\end{tabular}




\begin{tabular}{|c|c|c|c|c|c|}
\hline $\begin{array}{l}\text { 4) Stevens, } \\
\text { K.V., \& } \\
\text { Janke, J. } \\
\text { (2003) }\end{array}$ & $\begin{array}{l}\text { Evaluation of } \\
\text { breastfeeding } \\
\text { experiences of } \\
\text { active duty } \\
\text { women stationed } \\
\text { at a Midwestern } \\
\text { Air Force base. } \\
\mathrm{N}=9\end{array}$ & $\begin{array}{l}\text { Qualitative using } \\
\text { unstructured } \\
\text { interviewing methods. } \\
\text { Level VI }\end{array}$ & none & $\begin{array}{l}\text { - overall positive } \\
\text { perception of } \\
\text { breastfeeding } \\
\text { support in the } \\
\text { workplace. } \\
\text { - } 4 \text { main issues } \\
\text { were identified as } \\
\text { common barriers } \\
\text { to breastfeeding } \\
\text { after returning to } \\
\text { work: } \\
\text { 1) pumping issues } \\
\text { 2) temporary duty } \\
\text { issues (TDY) } \\
\text { 3) common } \\
\text { breastfeeding } \\
\text { issues } \\
\text { 4) military/civilian } \\
\text { differences }\end{array}$ & $\begin{array}{l}\text {-small sample size } \\
\text { - one research site } \\
\text { - one branch of } \\
\text { service (AF) }\end{array}$ \\
\hline $\begin{array}{l}\text { 5) Haas, } \\
\text { Howard, } \\
\text { Christopher, } \\
\text { Rowan, } \\
\text { Broga, \& } \\
\text { Corey } \\
(2006)\end{array}$ & $\begin{array}{l}\text { Assess factors } \\
\text { associated with } \\
\text { breastfeeding } \\
\text { rates in the early } \\
\text { postpartum } \\
\text { period and } \\
\text { breastfeeding } \\
\text { success among } \\
\text { AD and military } \\
\text { dependent } \\
\text { population. } \\
\mathrm{N}=934\end{array}$ & $\begin{array}{l}\text { Prospective cross- } \\
\text { sectional survey prior to } \\
\text { and after } \\
\text { implementation of } \\
\text { lactation service. } \\
\text { Level IV }\end{array}$ & $\begin{array}{c}\text { Establishment } \\
\text { of a lactation } \\
\text { service. }\end{array}$ & $\begin{array}{l}\text { - Prior BF was } \\
\text { predictor of } \\
\text { continuation of BF } \\
\text { at } 6 \text { weeks (OR } \\
2.04 \text { ). } \\
\text { - Higher education } \\
\text { level predicted } \\
\text { continuation of BF } \\
\text { at } 6 \text { months (OR } \\
2.55 \text { ). } \\
\text { - BF rates } \\
\text { increased after } \\
\text { establishment of } \\
\text { lactation service. } \\
\text { - AD women had } \\
\text { lower BF rates } \\
\text { than dependents } \\
\text { at } 6 \text { months } \\
\text { despite having } \\
\text { similar initiation } \\
\text { rates at discharge. }\end{array}$ & $\begin{array}{l}\text { - Irregularity of } \\
\text { Lactation } \\
\text { consultant visits } \\
\text { among the study } \\
\text { participants, } \\
\text { which could have } \\
\text { influenced } \\
\text { breastfeeding } \\
\text { rates and results. } \\
\text { - Small percentage } \\
\text { of AD mothers. } \\
\text { - Exclusive BF } \\
\text { rates not } \\
\text { assessed. }\end{array}$ \\
\hline $\begin{array}{l}\text { 6) Rishel \& } \\
\text { Sweeney } \\
(2005)\end{array}$ & $\begin{array}{c}\text { Comparison of } \\
\text { Breastfeeding } \\
\text { Rates in military } \\
\text { treatment } \\
\text { facilities with and } \\
\text { without lactation } \\
\text { consultants. } \\
\mathrm{N}=507 \text { total }\end{array}$ & $\begin{array}{l}\text { Retrospective chart } \\
\text { review at } 2 \text { Air Force } \\
\text { Military Treatment } \\
\text { Facilities (MTFs) and } 1 \\
\text { Navy MTF. } \\
\text { Level VI }\end{array}$ & None. & $\begin{array}{l}\text { - Breastfeeding } \\
\text { rates at all } \\
\text { facilities fell short } \\
\text { of HP } 2010 \\
\text { breastfeeding } \\
\text { goals at } 6 \text { months. } \\
\text { - Breastfeeding } \\
\text { initiation rates }\end{array}$ & $\begin{array}{l}\text { - Only } 3 \text { facilities } \\
\text { evaluated. } \\
\text { - Only } 46 \text { subjects } \\
\text { were AD mothers. } \\
\text { - No Army facilities } \\
\text { evaluated. }\end{array}$ \\
\hline
\end{tabular}




\begin{tabular}{|c|c|c|c|c|c|}
\hline & $(N=46 \mathrm{AD})$ & & & $\begin{array}{l}\text { were higher for } \\
\text { women who } \\
\text { interacted with } \\
\text { LCs after delivery } \\
\text { ( } P<0.0001 \text { ) } \\
\text { - There was no } \\
\text { significant } \\
\text { difference in BF } \\
\text { initiation and } \\
\text { duration rates for } \\
\text { infants delivering } \\
\text { at facilities with or } \\
\text { without LCs } \\
\text { ( } P>.05) \text {. } \\
* * B F \text { rates higher } \\
\text { for subjects }>27 \\
\text { years of age } \\
\text { ( } P<.05 \text { ). } \\
* * B F \text { rates higher } \\
\text { for mothers with } \\
\text { higher levels of } \\
\text { education } \\
\text { ( } P<.05 \text { ). } \\
* * B F \text { rates lower } \\
\text { for AD mothers } \\
\text { ( } P<.05 \text { ). }\end{array}$ & \\
\hline $\begin{array}{l}\text { 7) Uriell, } \\
\text { Perry, Kee } \\
\& \text { Burress }\end{array}$ & $\begin{array}{l}\text { Stratified random } \\
\text { sampling of active } \\
\text { duty Navy men } \\
\text { and women (all } \\
\text { pay grades) via } \\
\text { the annual } 2005 \\
\text { Pregnancy and } \\
\text { Parenthood } \\
\text { Survey with } \\
\text { additional } \\
\text { questions added } \\
\text { for breastfeeding. } \\
\mathrm{N}=4783 \text { AD Navy } \\
\text { women }\end{array}$ & $\begin{array}{c}\text { Descriptive, } \\
\text { exploratory, cross- } \\
\text { sectional survey } \\
\text { Level VI }\end{array}$ & None & $\begin{array}{l}\text { - Approx. half of } \\
\text { enlisted women } \\
\text { and one-third of } \\
\text { officers stated } \\
\text { they were not } \\
\text { given a } \\
\text { comfortable and } \\
\text { secluded location } \\
\text { to } \\
\text { breastfeed/pump } \\
\text { when returning to } \\
\text { work. } \\
\text { - two-thirds of } \\
\text { enlisted women } \\
\text { and approx. half } \\
\text { of officers } \\
\text { stopped } \\
\text { breastfeeding due } \\
\text { to work related } \\
\text { issues. } \\
\text { - 13\% of enlisted } \\
\text { women who }\end{array}$ & $\begin{array}{l}\text { Limited to Navy } \\
\text { service women }\end{array}$ \\
\hline
\end{tabular}




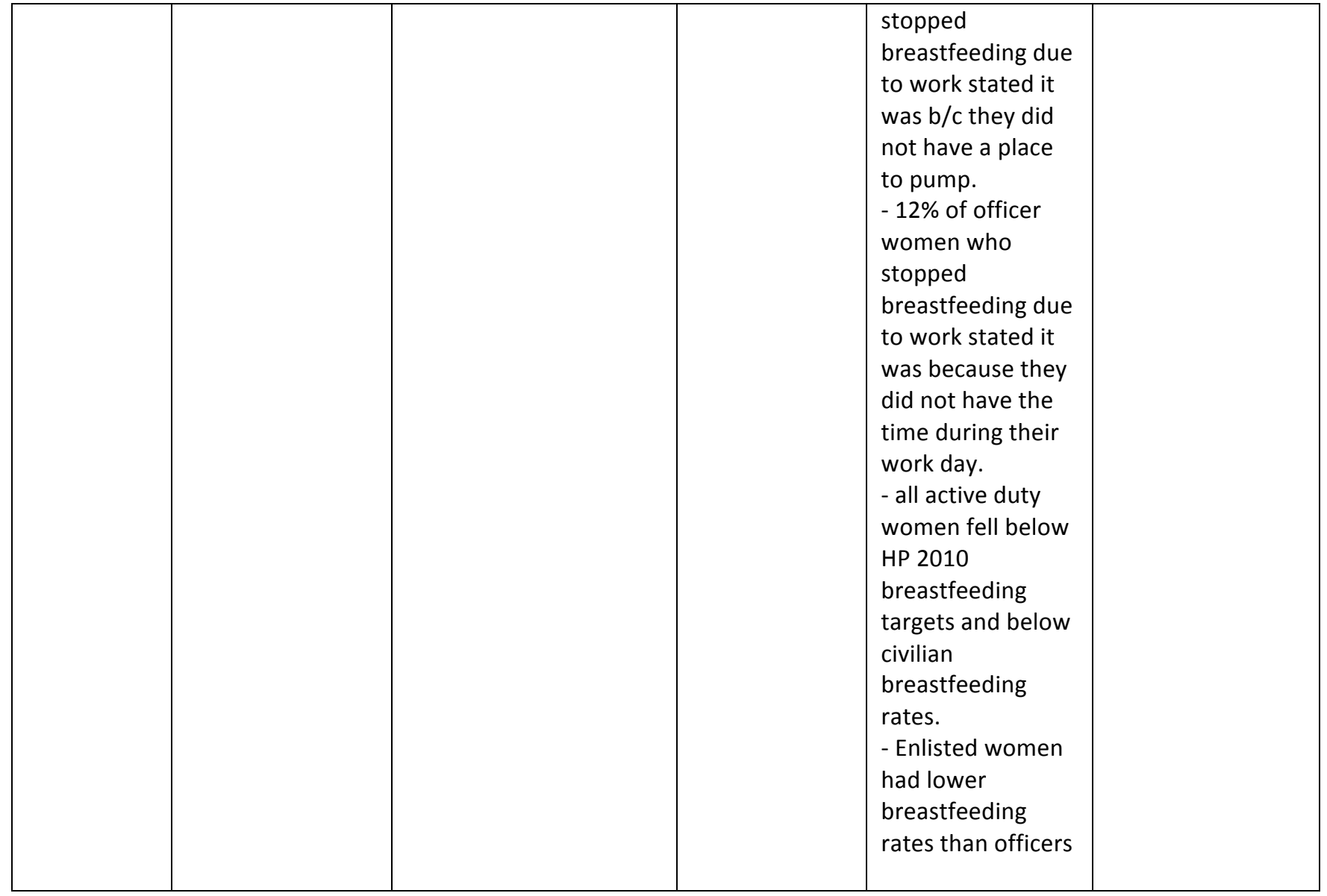


Appendix B

Permission to Use WBSS

MARTIN, SARAH E Maj USAF ACC 633 MSGS/SGCS

$\begin{array}{ll}\text { From: } & \text { Sarah Martin <sem2cu@virginia.edu> } \\ \text { Sent: } & \text { Saturday, January 11, 2014 1:35 PM } \\ \text { To: } & \text { MARTIN, SARAH E Maj USAF ACC 633 MSGS/SGCS } \\ \text { Subject: } & \text { Fwd: Workplace Breastfeeding Support Scale (WBSS) }\end{array}$

Forwarded message

From: Yeon Bai <baiy@mail.montclair.edu>

Date: Mon, Nov 4, 2013 at 9:49 PM

Subject: Re: Workplace Breastfeeding Support Scale (WBSS)

To: Sarah Martin <sem2cu@virginia.edu>

Sarah

thank you for your interest. I have used WBSS in another study but modified the items by combining with other scales. it has been accepted but not out yet as published.

you have my permission to use the scale. FYl: there has been multiple requests asking for permission to use the scale for the past 5-6 years, and hopefully some of them cited my work so you know.

Yeon

On Nov 4, 2013, at 3:13 PM, Sarah Martin <sem2cu@virginia.edu> wrote:

$>$ Dr. Bai,

$>$

$>$ I am a Doctor of Nursing Practice (DNP) student at the University of Virginia and was interested in using your WBSS to assess the perceived workplace support in active duty women serving in the U.S. military. I have done an extensive literature review, but have not been able to find any other articles using the WBSS. Have you published any other work using the WBSS since 2008?

>Also, do I have your permission to adapt the WBSS to my population of military women?

$>$

$>$ I appreciate your time and attention towards my degree research.

$>$

$>$ respectfully,

$>$ Sarah E Martin, Major, USAF

$>$ CNM/WHCNP

$>$ DNP student, UVA 


\section{Appendix C}

\section{Workplace Breastfeeding Support Scale}

Directions: For each of the following statement, circle the number which shows the strength of your feeling which may range from strongly disagree (SD) to strongly agree (SA). Your honest response is greatly appreciated.

\begin{tabular}{|c|c|c|c|c|c|c|c|c|}
\hline \multicolumn{7}{|c|}{$\begin{array}{l}\text { Strongly } \\
\text { Disagree }\end{array}$} & \multicolumn{2}{|c|}{$\begin{array}{l}\text { Strongly } \\
\text { Agree }\end{array}$} \\
\hline 1. & $\begin{array}{l}\text { My co-workers agree that breastfeeding is better for } \\
\text { baby's health than formula feeding. }\end{array}$ & 1 & 2 & 3 & 4 & 5 & 6 & 7 \\
\hline 2. & $\begin{array}{l}\text { I have supportive co-workers who cover for me when I } \\
\text { need to pump my milk. }\end{array}$ & 1 & 2 & 3 & 4 & 5 & 6 & 7 \\
\hline 3. & $\begin{array}{l}\text { My co-workers do not make fun of me when I sometimes } \\
\text { leak milk through my clothes. }\end{array}$ & 1 & 2 & 3 & 4 & 5 & 6 & 7 \\
\hline 4. & Breastfeeding is common in my workplace. & 1 & 2 & 3 & 4 & 5 & 6 & 7 \\
\hline 5. & I have a breastfeeding supportive supervisor. & 1 & 2 & 3 & 4 & 5 & 6 & 7 \\
\hline 6. & $\begin{array}{l}\text { My co-workers listen to me talk about my breastfeeding } \\
\text { experience. }\end{array}$ & 1 & 2 & 3 & 4 & 5 & 6 & 7 \\
\hline 7. & $\begin{array}{l}\text { I feel comfortable taking several breaks during work } \\
\text { hours to pump breast milk. }\end{array}$ & 1 & 2 & 3 & 4 & 5 & 6 & 7 \\
\hline 8. & $\begin{array}{l}\text { In my workplace, there is a designated space (nursing } \\
\text { room) to nurse my baby or pump breast milk. }\end{array}$ & 1 & 2 & 3 & 4 & 5 & 6 & 7 \\
\hline 9. & $\begin{array}{l}\text { I can easily find a quite place other than the bathroom at } \\
\text { my work to pump breast milk. }\end{array}$ & 1 & 2 & 3 & 4 & 5 & 6 & 7 \\
\hline 10. & $\begin{array}{l}\text { My workplace has a refrigerator that I can use to store my } \\
\text { milk. }\end{array}$ & 1 & 2 & 3 & 4 & 5 & 6 & 7 \\
\hline 11. & $\begin{array}{l}\text { My workplace has a breast pump for nursing mothers to } \\
\text { use }\end{array}$ & 1 & 2 & 3 & 4 & 5 & 6 & 7 \\
\hline 12. & My workplace has an on-site daycare. & 1 & 2 & 3 & 4 & 5 & 6 & 7 \\
\hline
\end{tabular}


Appendix D

\section{Survey Invitation: imbedded on website/blog}

Active Duty Breastfeeding Mothers need your input!

If you are serving on active duty in any branch of the U.S. Armed Forces and have breastfed between 1 January 2010 and 30 September 2013, please go to the link below and answer a quick online survey about your perceptions about breastfeeding support. Please fill out only ONE survey, regardless of the number of children you breastfed within the dates listed!

Your responses will be kept completely anonymous. The survey is web-based and conducted by a third party vendor (SurveyMonkey). Your name will not be attached to any results and any personal identifying information is not collected. The survey is user-friendly and you should be able to complete it within 15-20 minutes or less.

I appreciate your willingness to participate and value your feedback!

The results will help evaluate perceptions of breastfeeding support for active duty women in the military and give guidance to improve any current policies or support programs to help prolong breastfeeding rates for active duty mothers. This is not an Air Force or Department of Defense (DoD) sponsored survey.

Thank you in advance!

Sarah E Martin, Major, USAF, NC

CNM/WHCNP

DNP Student, University of Virginia

To begin the survey, please click on the URL below. You can withdraw from the survey at any time before you submit the survey.

https://www.surveymonkey.com/s/WBSSactiveduty 


\section{Appendix E}

\section{Survey Monkey Permission Letter}

$\begin{array}{ll}\text { August 28, } 2013 & \text { SurveyMonkey } \\ & \begin{array}{l}\text { SurveyMonkey Inc. } \\ \text { www.surveymonkey.com }\end{array} \\ & \begin{array}{l}\text { For questions, email: } \\ \text { support@surveymonkey.com }\end{array}\end{array}$

Re: Permission to Conduct Research Using SurveyMonkey

To whom it may concern:

This letter is being produced in response to a request by a student at your institution who wishes to conduct a survey using SurveyMonkey in order to support their research. The student has indicated that they require a letter from SurveyMonkey granting them permission to do this. Please accept this letter as evidence of such permission. Students are permitted to conduct research via the SurveyMonkey platform provided that they abide by our Terms of Use, a copy of which is available on our website.

SurveyMonkey is a self-serve survey platform on which our users can, by themselves, create, deploy and analyze surveys through an online interface. We have users in many different industries who use surveys for many different purposes. One of our most common use cases is students and other types of researchers using our online tools to conduct academic research.

If you have any questions about this letter, please contact us at the email address above.

Sincerely,

SurveyMonkey Inc.

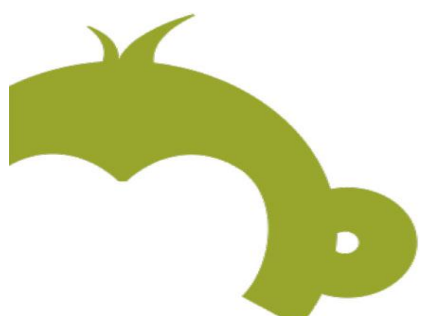

285 Hamilton Avenue, Suite 500, Palo Alto, CA 94301 | O: 650.543 .8400 | F: 650.289 .0335 111 SW 5th Ave, Suite 1600, Portland, OR 97204 | O:503.225.1202 | F: 503.225.1200 
Appendix F

Modified WBSS

\section{Breastfeeding Support for Active Duty Women}

\section{Survey Description}

The purpose of this research project is to assess the perception of breastfeeding support for women serving on active duty in the military. This is a research project being conducted by Sarah Martin at the University of Virginia as part of Doctor of Nursing Practice (DNP) degree completion. This is not an Air Force or Department of Defense (DoD) sponsored survey.

You are invited to participate in this research project if you are/were serving on active duty in any branch of the United States military and breastfed one or more children between 1 January 2010 to 30 September 2013 . Please only fill out ONE survey per participant, regardless of how many children you breastfed during this timeframe.

Your participation in this research study is voluntary. You may choose not to participate. If you decide to participate, you may withdraw at any time prior to submitting the survey. After survey submission you will no longer be able to withdraw from the study due to anonymity of survey responses. If you decide not to participate in this study. you will not be penalized.

The procedure involves filling out an online survey that will take approximately 15-20 minutes or less. Your responses will be anonymous and we do not collect identifying information such as your name, email address or IP address. The survey questions involve your perception of breastfeeding support after returning to duty to determine possible areas of improvement for breastfeeding support policies and programs for active duty women. The overall goal is to improve duration of breastfeeding for active duty women, thus improving the health of military women and children and reducing healthcare costs.

We will do our best to keep your information anonymous. All data will be stored in a password protected electronic format. To help protect your anonymity, the surveys will not contain information that will personally identify you. The results of this study will be used for scholarly purposes only and may be shared with University of Virginia representatives.

If you have any questions about the research study. please contact the primary researcher Sarah Martin at sem2cu@Virginia.edu. You may also contact the UVA faculty advisor, Dr. Emily Drake, at eje@Virginia.edu for any questions or concerns related to this survey or doctoral project. This research has been reviewed according to University of Virginia IRB procedures for research involving human subjects. The UVA IRB can be contacted at irbsb@virginia.edu regarding the IRB procedures related to this research study.

By proceeding with the survey, you are consenting that:

- you have read the above information and voluntarily agree to complete the survey

- you are at least 18 years of age and meet the criteria for the survey outlined above

If you do not wish to participate, simply exit the survey at this time. 
Breastfeeding Support for Active Duty Women

Demographic Information

The following 10 questions are to gain a better understanding of your active duty service and breastfeeding history.

1. What is your age?
○1-29
(0-39
O 4049
preser not to answer

\section{What is your ethnicity? (Please select all that apply.)}
Caucasaan, non-Hispanic
$\square$ Hispanic
$\square$ African American
$\square$ Asiant
$\square$ Ouner
prefer not to answer

3. What is the highest level of education you have completed?
High School
Some college
College Graduate
Post Graduale Degret
prefer nol to anewer

4. Were you eligible for Women, Infants, and Children (WIC) benefits while you were breastfeeding and serving on active duty?
mc eligible
wic eligible but did not use
Not Wic eligible
prefer not to answer 


\section{Breastfeeding Support for Active Duty Women}

5. What rank were you while breastfeeding and serving on active duty in the U.S. military?

$\bigcirc$ onticer

$\bigcirc$ Enlisted

Oprefer not to answer

6. What branch of the United States military have you served while breastfeeding?
Air Force
Parmy
$\bigcirc \mathrm{Navy}$
$\bigcirc$ Marines
$\bigcirc$ cosst Guard
preter not to answer

7. What is the best description of your duty location while breastfeeding?
$\bigcirc$ stateside (CONUS)
O merseas (OCCONus)
$\bigcirc$ prefer not to answer

8. How would you best describe your job function while breastfeeding and serving on active duty?

Primarily administrative
non-administratwe
prefer not to answer

9. Overall, would you say that you were able to meet your breastfeeding goals?
Y res
No
$\bigcirc$ prefer not to answer 


\section{Breastfeeding Support for Active Duty Women}

10. If you were not able to meet your breastfeeding goals, what was the primary reason?

Lack of eupport in workplace

Separation from baby due to mifilary duties (deployment, TOY, training exercises. etc)

Mlk supply iseves

Baby latch issues

oner

preter not to answer 


\section{Breastfeeding Support for Active Duty Women}

\section{Workplace Breastfeeding Support Scale}

The following 12 questions are to evaluate your perception of breastfeeding support while serving on active duty in the military.

1. My co-workers agree that breastfeeding is better for baby's health than formula feeding. STRONGLY DISAGREE<smiles>[CH]</smiles>

0

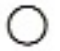

O

$\bigcirc$

STRONGLY AGREF

2. I have supportive co-workers who cover for me when I need to pump my milk.

STRONGLY DISACREE
O

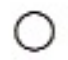

0

O

O

SIRONGLY Y AGREE

3. My co-workers do not make fun of me when I sometimes leak milk through my clothes. STRONGLY DISAGREE

O
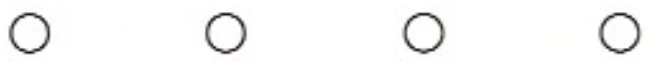

SIRONGI Y AGREE

4. Breastfeeding is common in my workplace.

STRONGLY DISAGREE

O

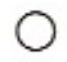

0

O

O

STRONGLY AGREE

5. I have a breastfeeding supportive supervisor.

SIRONGLY DISAGREE

O

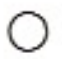

0

0

0

STRONGLY AGREE

6. My co-workers listen to me talk about my breastfeeding experience.

STRONGLY DISAGREE

$\bigcirc$
0

$\bigcirc$

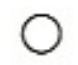

7. 1 feel comfortable taking several breaks during work hours to pump breast milk.

STRONGLY DISAGREE

$\bigcirc$
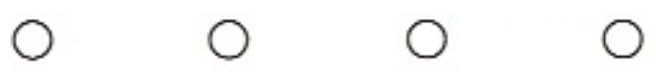

STRONGLYAGREE

8. In my workplace, there is a designated space (nursing room) to nurse my baby or pump breast milk.

STRONGLY

DISAGREE

O

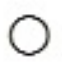

0

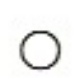

STRONGLY AGREE 


\section{Breastfeeding Support for Active Duty Women}

9. I can easily find a quiet place other than the bathroom at my work to pump breast milk. STRONGLY DISACREE O<smiles>[O-]</smiles>

$\bigcirc$

$\bigcirc$

O

SIRONGIY Y ACGREE

10. My workplace has a refrigerator that I can use to store my milk.

STRONGLY

IDISAGISTF-

O

O

$\bigcirc$

$\bigcirc$

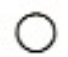

STRONGLY AGREE

11. My workplace has a breast pump for nursing mothers to use.

STRONGLY

DISAGREE

$\bigcirc$

0

$\bigcirc$

O

0

STRONGLY AGREE

12. My workplace has an on-site daycare (i.e. Child Development Center). STRONGLY DISACGREE O<smiles>O</smiles><smiles>[O]</smiles><smiles>[O]</smiles><smiles>[CH]</smiles> 


\section{Breastfeeding Support for Active Duty Women}

Final Question!

Please feel free to add anything about your breastfeeding experiences, positive or negative, that you have encountered while serving on active duty in the U.S. military.

1. Is there anything else you would like to share about your experiences breastfeeding in the military? 


\section{Breastfeeding Support for Active Duty Women}

\section{Thank you!}

Thank you for participating in this survey that will help with the completion of my doctoral capstone project and potentially heip improve breastfeeding support programs and policies for active duty wornen! Your honest responses are greatly appreciated!

\section{Please submit your survey!}

If you do not wish to do submit your survey, you may click the withdraw button below and exit the survey. Your responses will not be saved and you will not be penalized.

Withdraw

Stubmit 
Appendix G

\section{Survey Close Announcement}

"Thanks to everyone who participated in the survey for Active Duty Women's Perceptions of Breastfeeding Support in the Military Setting". There was an impressive response rate from all branches of the military and the results will not only help with the completion of my doctoral capstone project, but hopefully guide future breastfeeding policies and programs throughout the Department of Defense. The results will be made available in June-July 2014 as well as publication information on this website/blog. Information will also be updated regarding the results on the Facebook page www.facebook.com/activedutybreastfeeding.com. You can also go to this Facebook page to contact the primary researcher (Sarah Martin, RN, CNM, WHCNP) and provide any comments/suggestions. Thank you!" 
Appendix $\mathrm{H}$

IRB-SBS Exemption Letter

January 31, 2014

Sarah Martin and Emily Drake

Academic Divisions

PO Box 800826

Dear Sarah Martin and Emily Drake:

Thank you for submitting your project entitled: "Active Duty Women's Perception of Breastfeeding Support in the Military Setting" for review by the Institutional Review Board for the Social \& Behavioral Sciences. The Board reviewed your Protocol on January 31, 2014.

The first action that the Board takes with a new project is to decide whether the project is exempt from a more detailed review by the Board because the project may fall into one of the categories of research described as "exempt" in the Code of Federal Regulations. Since the Board, and not individual researchers, is authorized to classify a project as exempt, we requested that you submit the materials describing your project so that we could make this initial decision. As a result of this request, we have reviewed your project and classified it as exempt from further review by the Board for a period of four years. This means that you may conduct the study as planned and you are not required to submit requests for continuation until the end of the fourth year.

This project \# 2014-0019-00 has been exempted for the period January 31, 2014 to January 30,2018 . If the study continues beyond the approval period, you will need to submit a continuation request to the Board. If you make changes in the study, you will need to notify the Board of the changes.

Sincerely,

Tonya R. Moon, Ph.D.

Chair, Institutional Review Board for the Social and Behavioral Sciences 
Appendix I

Manuscript

Pages: 22

Words: 3620

Tables: 3

Figures: 2

Appendix: 0

References: 13

Contact: Major Sarah E. Martin

Email: solive22@aol.com

Guarantor: Major Sarah E. Martin

\title{
Active Duty Women's Perceptions of Breastfeeding Support in the Military Setting
}

\author{
${ }^{1}$ Major Sarah E. Martin, NC USAF \\ ${ }^{2}$ Dr. Emily Drake, PhD, RN \\ ${ }^{3}$ Dr. Laura Yoder, $\mathrm{PhD}, \mathrm{RN}$ \\ ${ }^{4}$ Dr. Mary Gibson, PhD, RN \\ ${ }^{5}$ Major Carrie Ann Litke, MC, USAF
}

Address Correspondence to 133 Bowen Street, Hampton, VA 23665

Email: solive22@aol.com Phone:(703) 899-9318

${ }^{1}$ Certified Nurse Midwife, United States Air Force, 133 Bowen St., Hampton, VA 23665

${ }^{2}$ Associate Professor, University of Virginia, School of Nursing, Department of Family, Community \& Mental Health Systems, CMNEB 3007, Charlottesville, VA 22903-3388

${ }^{3}$ Assistant Professor, Eastern Mennonite University, 1200 Park Road, Harrisonburg, VA 22801

${ }^{4}$ Associate Professor, University of Virginia, School of Nursing, Department of Family, Community \& Mental Health Systems, CMNEB 2107, Charlottesville, VA 22903-3388

${ }^{5}$ Staff Pediatrician, United States Air Force, 1245 Phantom Valley Street, San Antonio, TX 78232

Keywords: Breastfeeding, Military, Policy, Support

Presented as Capstone project for Doctor of Nursing Practice program completion at The University of Virginia, School of Nursing on 30 June 2014. 


\begin{abstract}
BACKGROUND

The purpose of this study is to evaluate the current perceptions of breastfeeding support for active duty women serving in the US Armed Forces.

\section{METHODS}

An online survey based on the Workplace Breastfeeding Support Scale (WBSS; Bai, Peng, \& Fly, 2008) was used to collect data from active duty military mothers. Data was collected and analyzed using SPSS software to evaluate active duty women's perceptions of breastfeeding support in the military.

\title{
RESULTS
}

Three hundred and eighteen active duty women participated in the online survey. The average Workplace Breastfeeding Support Scale scores for active duty women was $50.20(S D=15.75)$. Comparing WBSS scores and branch of service, women in the Army had significantly lower WBSS scores $(M=45.85)$ then women in the Air Force $(M=53.96, p<.001)$. Enlisted women had significantly lower scores $(M=47.12)$ than officers $(M=54.62, p<.001)$. Also noted were significantly lower scores of active duty women who were Hispanic $(M=44.30)$ and women who had lower levels of education $(M=46.90, p=.006)$.

\section{CONCLUSIONS}

The Department of Defense may be able to improve breastfeeding rates for all active duty mothers by implementing and adhering to lactation policies and focusing support efforts for enlisted women in all branches of service.

Keywords: Breastfeeding, military, policy, support 


\section{Introduction}

Breast milk is considered the "gold standard" of infant and child nutrition due to overwhelming scientific evidence supporting the health benefits for both mother and child (Eidelman \& Schanler, 2012). The increasingly acceptable social norms of breastfeeding in the US have helped create an upward trend in breastfeeding rates in the past decade. The significant increase in breastfeeding initiation rates, however, is overshadowed by the rapid decline in breastfeeding rates at six and twelve months (Bettinelli, 2012). The return to work after maternity leave is thought to contribute to the cessation of breastfeeding for many mothers due to an unsupportive work environment. Difficulty finding break time and a private place to express milk are often cited as the reasons for discontinuation of breastfeeding after returning to work (Feldman-Winter, 2013).

According to a survey prepared by the National Center for Veterans Analysis and Statistics (2011), a higher percentage of women Veterans ages 25 to 34 have children (59\%) compared to non-Veteran women of the same ages (52\%). Active duty women face similar breastfeeding issues as the general population in addition to having many other unique challenges specific to military employment. Long duty hours, inflexible work schedules, and frequent separations from baby and family can make it difficult for active duty mothers to continue breastfeeding after returning to work (Roche-Paull, 2010). The Department of Defense (DoD) recognizes the importance of breastfeeding and has endorsed Healthy People 2020 target goals for health promotion and disease prevention (DoD Instruction 1010.10, 28 April 2014). However, a DoD wide lactation policy does not exist. Therefore, each branch of service has implemented lactation policies or support recommendations for their respective service members 
in an effort to support breastfeeding and optimize the health of military members and their families. See Table 1 for a summary of military lactation policies.

\section{Purpose of this Study}

The purpose of this study is to evaluate the current perceptions of breastfeeding support for active duty women serving in the US Armed Forces, to identify barriers to breastfeeding, and to assess current lactation policies and programs throughout the DoD. The results can be used to help guide breastfeeding policy development and implementation, develop breastfeeding education materials for both breastfeeding women and supervisors, and close the gaps of breastfeeding support between military women and the general population.

\section{Methods}

\section{Brief Introduction}

The increasing awareness of the health and financial benefits of breastfeeding has encouraged many military services to implement lactation policies and support programs in accordance with the US Surgeon General's Call to Action to Support Breastfeeding (2011). Current perceptions of the effectiveness of these policies and programs is needed to ensure active duty women are getting the breastfeeding support they need to improve duration rates. The aim of this capstone is to evaluate the perceptions of breastfeeding support in the workplace for active duty women to identify gaps and provide recommendations that can improve current policies and support programs.

\section{Research Design}

A cross-sectional survey design was used to assess breastfeeding support in the military. Questions for the survey were adapted from the Workplace Breastfeeding Support Scale (WBSS), 
a short questionnaire designed to measure mothers' perceived support for breastfeeding from the workplace that has been tested and proven acceptable for both reliability $($ alpha $=.77)$ and validity (Bai, Peng, \& Fly, 2008). Responses are measured on a 7-point Likert scale with a high score indicating a more positive perception of workplace breastfeeding support. The lowest possible score is 12 and the highest possible score is 84 .

\section{Setting of Project}

Participants could access the online survey from anywhere in the world that had computer and Internet access. Participants who met inclusion criteria were invited to take the survey if they were serving on active duty in any branch of the United States military and breastfed one or more children between 1 January 2010 and 30 September 2013.

Beginning 1 February 2014, the direct link to the Survey Monkey self administered survey was posted on a Facebook page entitled "Breastfeeding Support for Active Duty Mothers" and e-mailed to local breastfeeding support group leaders.

\section{Protection of Human Subjects}

The University Institutional Review Board (IRB-SBS) was consulted and the project was considered exempt. The survey invitation and consent stated that participation was voluntary and this study was not affiliated with the Department of Defense or any military branch. The consent page further disclosed that no personal identifiable information would be collected in the survey and all responses would be kept anonymous. No compensation was offered and participants were informed that they could exit the survey at any time as well as withdraw at the end of the survey if they did not want their responses collected. For each demographic question in the survey, participants were given the option "prefer not to answer". Participants were further assured that 
there would be no efforts made to identify or contact them and there would be no retaliation or negative consequences for declining to participate or withdrawing from the survey.

\section{Results}

\section{Sample}

The sample consisted of a total of 318 respondents to the online survey from the five branches of the U.S. military (Army, Air Force, Navy, Marine Corps, Coast Guard). The demographic characteristics of the 318 subjects are shown in Table 2 . The majority of active duty military all-female participants were in the $21-29$ year age range $(n=164 ; 51.6 \%)$. Over $75 \%$ of participants were Caucasian $(n=254)$, followed by Hispanic non-white $(n=38 ; 12 \%)$, and Other- non-Hispanic $(n=20 ; 6 \%)$. While a majority had completed some college ( $n=113$; $36 \%)$ or were college graduates $(n=107 ; 34 \%)$, some had post graduate degrees $(n=78 ; 24 \%)$. A vast majority did not meet low-income eligibility for WIC assistance ( $n=256 ; 81 \%)$. A higher percentage of participants held enlisted rank $(n=182 ; 57 \%)$ than officer rank $(n=132 ; 42 \%)$. There were participants from each branch of service with the majority in the Air Force ( $n=120$; $38 \%)$ and Army $(n=116 ; 37 \%)$ followed by Navy $(n=51 ; 16 \%)$, Marines $(n=18 ; 6 \%)$, and Coast Guard $(n=13 ; 4 \%)$. A majority of participants were stationed stateside ( $n=260 ; 82 \%)$ and many had primarily administrative duties ( $n=174 ; 55 \%)$ while breastfeeding. Overall, a majority of participants stated that they were able to meet their breastfeeding goals $(n=205 ; 65 \%)$. Those that stated that they were not able to meet their breastfeeding goals $(n=107 ; 34 \%)$ selected lack of support in the workplace being the primary reason $(n=45 ; 14 \%)$ followed closely by milk supply issues $(n=43 ; 13.5 \%)$ and separation from baby due to military duties (deployments, Temporary Duty Assignments (TDYs), training exercises, etc.) $(n=40 ; 12.6 \%)$. 
Chi-square tests for differences in proportions revealed that there were some statistically significant differences in demographic characteristics of the sample participants depending on different branches (Army, Air Force, Navy/Marines) and between the two ranks (Enlisted vs. Officer). For example, the proportion of White, Non-Hispanic was much lower in the Army $(67.8 \%)$ than in the Air Force (82.1\%) and the Navy/Marines (80.9\%). Also the proportion of those with only a High School or some college education was much higher in the Navy/Marines (56.5\%) than in the Air Force (35.3\%) and in the Army (37.9\%). While there was no difference

in ethnicity by rank, enlisted participants were more likely to be under age 30, have achieved less education, and were more likely to be WIC eligible.

\section{WBSS Scores and Selected Demographic Variables}

The Workplace Breastfeeding Support Scale (WBSS), scores ranged from 12 to 84 with higher scores indicating a higher perception of breastfeeding support in the workplace. The overall average WBSS score in this sample was $50.20(S D=15.75)$. The WBSS was tested for reliability in this sample with a Cronbach's alpha of 0.85 , indicating good internal consistency reliability (Nunnally \& Bernstein, 1994).

Differences among WBSS scores were evaluated using one-way ANOVA for particular demographic groups. Among the three level ethnic/race groups (Hispanic, White- Non-Hispanic, Other- non-Hispanic) WBSS scores differed significantly across the three groups, $F(2,287)=$ $3.67, p=.027$. Bonferonni post-hoc comparisons of the three groups indicated that the Hispanic group $(M=44.30,95 \%$ CI $[38.50,50.09])$ had significantly lower WBSS scores than the White, non-Hispanic group $(M=50.80,95 \% \mathrm{CI}[48.77,52.84])$ and the Other- non-Hispanic group $(M=$ 
53.81, 95\% CI [48.64,58.97]). Both of the non-Hispanic groups (White and Other) did not significantly differ from each other in WBSS scores at $p<.05$.

WBSS differences among three groups differentiated by education level (High School/Some College, College Graduate, Graduate Degree) were also calculated using one-way ANOVA. WBSS scores differed significantly across the three groups, $F(2,291)=5.148, p$ $=.006$. Bonferonni post-hoc comparisons of the three groups indicated that the High School/Some College group $(M=46.90,95 \%$ CI $[43.99,49.81])$ had significantly lower WBSS scores than the group with Graduate Degrees $(M=53.94,95 \%$ CI $[50.41,57.48])$, but did not significantly differ from the group of College Graduates $(M=51.45,95 \%$ CI $[48.45,54.45])$. The WBSS scores of College Graduates and those with Graduate Degrees did not significantly differ at $p<.05$.

\section{WBSS Scores and Military Service}

Before conducting a 2-way ANOVA of WBSS scores depending on branch of service and rank, the item assessing military branch was re-coded to reflect three groups (Army, Air Force, and Navy/Marines), so that adequate group size was present. The few respondents who were part of the Coast Guard $(n=13)$ were treated as missing in the analysis because their group size was too small for meaningful comparison. Navy and Marines were combined because they are considered "sister services" that have similar policies and command structure. A consort diagram summarizing the loss of sample size for the two-way ANOVA can be seen in Figure 1. The univariate and multivariate distribution of the WBSS scores by participant rank and military branch were assessed as normal with no outliers. There was homogeneity of variances, as 
assessed by Levene's Test of Homogeneity of Variance $(p=.61)$. See Table 3 to evaluate the estimated marginal means of WBSS scores for rank and branch of service.

The results of the 2-way ANOVA indicated that there was no significant interaction effect of rank by branch $\left(F(2,275)=.902, p=.407\right.$, partial $\left.\eta^{2}=.007\right)$. There was, however, a statistically significant difference in mean WBSS scores depending on rank (officers vs. enlisted), $F(1,277)=15.67, p<.001$, partial $\eta^{2}=.05$. Officers had higher WBSS scores $(M=54.62)$ than enlisted $(M=47.12)$. There was also a statistically significant difference in mean WBSS scores depending on branch of service (Air Force, Army, Navy/Marines), $F(2,277)=8.37, \mathrm{p}<.001$, partial $\eta^{2}=.06$. While the mean WBSS scores did not differ significantly between the Air Force and the Navy/Marines $(M=52.80)$ nor between the Army and the Navy/Marines, the mean WBSS score of the Army $(M=45.85)$ was significantly lower than the Air Force mean WBSS score $(M=53.96, p<.001)$. The effect sizes $\left(\eta^{2}\right)$ reflect a medium magnitude of the effect of rank and branch in explaining variability of WBSS scores in this sample.

Officers and enlisted personnel in the Air Force had the highest perception of workplace breastfeeding support with average scores of 58.9 (officer) and 49.0 (enlisted). The Navy \& Marines had slightly lower perceptions of workplace breastfeeding support scoring 56.9 (officers) and 48.7 (enlisted). Army officer and enlisted personnel had the lowest perception of workplace breastfeeding support scoring 48.1 (officer) and 43.6 (enlisted) on the WBSS. Overall, the officers averaged a 7.5-point higher WBSS score than enlisted.

A comparison of scores per WBSS question and each branch of service was evaluated. The WBSS question that had the highest average score for perception of workplace breastfeeding support was "My workplace has a refrigerator that I can use to store my milk" (5.41) followed by 
"My co-workers agree that breastfeeding is better for baby's health than formula feeding" (5.20). The WBSS question, "My workplace has a breast pump for nursing mothers to use" had the lowest average score (1.79).

\section{Qualitative Analysis}

At the end of the survey, one open-ended item was included: "Is there anything else you would like to share about your experiences breastfeeding in the military?" Over 190 participants responded. While this data was not formally analyzed, common themes were identified using Survey Monkey Text Analysis software. The four primary keywords identified were "months" ( $n=43 ; 21.61 \%)$, "nursing" $(n=41 ; 20.60)$, "room" ( $n=37 ; 18.59 \%)$, and "baby" $(n=35 ; 17.59 \%)$. These keywords were used to identify common themes that expressed positive and/or negative support for breastfeeding in the military setting. Lactation policy implementation, duty requirements, and lack of support were three common themes identified.

In spite of policies in place that require nursing mothers have a time and a place to pump, a majority of respondents stated that the lack of time and space for pumping was the primary obstacle. According to one active duty mother, "The hardest thing that I have encountered is actually finding a place beside a bathroom or hiding in my car to pump". Many active duty mothers stated that despite lactation policies in place, the lack of support from co-workers and supervisors had a negative influence on their decision to continue breastfeeding:

While nursing, some co-workers would complain that I had to pump. They felt that I was nursing to get out of work. At times, finding a room to nurse in was not easy-I had to wait for a room to open up; also, there were times I would have to pump later than I should have because I was busy and felt like I had to pick up more slack because I was going to 
pump. We have [Air Force Instructions] (AFIs) to support nursing; however, education for everyone and the support given could be improved for those of us who do nurse.

Despite many obstacles experienced by active duty women regarding workplace lactation support, approximately half of the respondents described positive breastfeeding experiences and support from co-workers or supervisors in military settings:

So far I've been fortunate to have a wonderful experience. My command team has been very supportive and flexible with me pumping and breastfeeding. They've allowed for me to have assistance when pumping during an FTX, breastfeed in uniform on multiple occasions, and allow me to educate the other pregnant soldiers in the unit on breastfeeding and working. Though there was no designated pumping room and I was walked in on/forced to pump in the restroom many times I still feel very fortunate that I was able to make it to my first goal. $(13+$ months now!)

\section{Discussion}

The results of the online survey showed that current perceptions of breastfeeding support among active duty women are divided between positive and negative perceptions. Compared to previous studies, since the majority of active duty mothers reported they were able to meet their breastfeeding goals, the results also indicated favorable breastfeeding support in military settings. Participant responses did, however, identify multiple barriers to breastfeeding support that persist despite lactation policy implementation throughout the DoD. Figure 2 summarizes the demographic characteristics of active duty women with significantly lower perceptions of breastfeeding support in military settings per the WBSS survey.

\section{Perceptions of Breastfeeding Support and Demographics}


A Morbidity and Mortality Weekly Report (MMWR) published by the Center for Disease Control and Prevention (CDC) discusses the many factors that influence breastfeeding initiation and duration including race/ethnicity, education, age, and income (2013). Minorities, younger age, less maternal education, and lower income levels are all characteristics associated with lower breastfeeding prevalence (Grummer \& Shealy, 2009). Similarly, the active duty women who participated in this study who are Hispanic, less than 30 years of age, have lower education levels, and lower income had lower perceptions of breastfeeding support.

Race/Ethnicity. Hispanic active duty women who participated in this survey had significantly lower perceptions of breastfeeding support than White, non-Hispanic participants. Comparisons with African Americans were not possible due to low AA participation ( $\mathrm{n}=20$; 6.3\%). It's possible that the low AA active duty participation rate is somewhat a reflection of the low prevalence of AA breastfeeding in the general population. The National Immunization Survey (NIS) reported that for births between 2000 and 2008, breastfeeding for AA infants fell significantly below white, non-Hispanic and Hispanic breastfeeding rates (2012).

According to the MMWR report on ethnic disparities in breastfeeding rates (CDC, 2013), the persistent gap in breastfeeding rates among AA women and other ethnic and racial groups in the U.S. might be an indication of unsupportive cultural norms, perceptions that breastfeeding is inferior to formula, a lack of partner support, or unsupportive work environments. Further investigation into the ethnic differences in breastfeeding rates and the perceptions of breastfeeding support should be done in military settings so the educational and support needs of all active duty women can be met. 
Rank. The association of rank with perceptions of breastfeeding support likely reflects the demographic characteristics of military members. Military officers have higher levels of education, higher income levels, and are older $(>30)$ than enlisted members on average (Office of the Deputy Assistant Secretary of Defense, 2012). Officers, in general, have more autonomy and control over their work environment. Therefore, it was not surprising that active duty mothers who are officers had significantly higher perceptions of breastfeeding support than enlisted mothers in all branches of service. In addition, active duty mothers with graduate degrees had significantly higher perceptions of breastfeeding support than active duty mothers with lower levels of education (i.e. high school diploma and/or some college). These findings indicate that specific attention to the breastfeeding support needs of enlisted women should be emphasized in policy implementation throughout the DoD.

\section{Service Disparities}

Air Force women (officer and enlisted) had the highest perceptions of breastfeeding support followed by women in the Navy and Marines. Active duty women in the Army had the lowest perceptions of breastfeeding support. The lack of a formal lactation policy for Army soldiers is a possible contributor to the low WBSS scores. The findings could be used to increase awareness of the need for a formal lactation policy in the Army. In addition, the demographic characteristics of participants in each branch of service could also be indicative of WBSS scores. For example, the Army had the highest proportion of participants that were Hispanic $(n=22 ; 19.1 \%)$. Since being Hispanic was associated with lower WBSS scores, it's possible that some of the variation in WBSS scores for the Army participants was explained by race/ethnicity and not by branch of the military. 
The Air Force had the highest proportion of participants that were White, NonHispanic $(n=96 ; 82.1 \%)$ and had either a college degree $(n=42 ; 35.3 \%)$ or a graduate degree $(n=$ $35 ; 29.4 \%$ ). It's likely that higher WBSS scores in the Air Force is somewhat related to the higher proportion of White, Non-Hispanics and more highly educated participants. While it is difficult to parse out the effects of race/ethnicity and education from the effects of military branch on WBSS scores, it is clear that the breastfeeding support within the Army could be improved.

Social and cultural acceptance of breastfeeding in military settings will improve as accommodations and policies for active duty breastfeeding mothers are standardized and enforced throughout the DoD. Breastfeeding support policies should be promoted and enforced in military settings similar to other healthy behaviors such as diet and exercise to ensure the health and well-being of sailors, soldiers, airmen and marines and their families. TRICARE coverage of breast pumps and supplies for all military beneficiaries would help provide breastfeeding support for all military beneficiaries similar to the PPACA and coverage for the general population. Finally, hospital grade breast pumps and supplies could be made available in DoD facilities that have a significant number of active duty females.

\section{Strengths of the Study}

Previous studies evaluating breastfeeding policies and support programs in military settings have been limited by the low numbers of active duty participants, the small number of military installations evaluated, or the focus on one particular branch of service. The online survey method enabled accessibility for women in all branches of the military at various installations around the world. This increased the generalizability of the results across military 
ranks and services.

The brevity and convenience of the online survey aimed to encourage participation and serve as a foundation to guide future research. The combination of demographic questions and the WBSS used in this survey provide valuable data that can be easily replicated and used for ongoing evaluation of breastfeeding support for active duty women.

\section{Conclusion}

Despite the valuable information obtained in this study on gaps in breastfeeding support for active duty mothers, the 12-question WBSS does not provide a comprehensive evaluation of all factors that can affect the perceptions of breastfeeding support. For example, the amount of lactation support provided by military healthcare workers, family separation influences on lactation, and social norms in military settings could have direct and indirect influences on lactation practices for active duty women that are not fully assessed by the WBSS and warrant further investigation. In addition, the retrospective, cross- sectional survey does not account for WBSS score variations over time. Therefore, the survey could be administered to active duty mothers at different stages of breastfeeding to identify where support is needed most.

Military nurses are in key positions to promote and support lactation programs as well as provide education on the importance of breastfeeding from patients to policy makers. This study shows that active duty military mothers who are enlisted rank, Hispanic ethnicity, have lower education levels, and in the Army have lower perceptions of breastfeeding support. Nurses in military settings can improve perceptions of breastfeeding support in these particular demographics by focusing efforts to improve workplace support programs designed to target these populations. 
References

Air Force Instruction (AFI) 44-102. Section 4.16: Breastfeeding and Breast Pumping (1 May 2006, revised 20 Jan 2012). Medical Care Management by order of the Secretary of the Air Force.

Army Regulation (AR) 40-501 (2007). Standards of Medical Fitness, Pregnancy and Postpartum Profiles. AR 614-30: Assignments, Details, and Transfers, Overseas Service in Pregnancy. 600-8-10: Leaves and Passes, Postpartum Convalescent Leave.

Bai, Y., Peng, J., \& Fly, A. (2008). Validation of a short questionnaire to assess mother's perception of workplace breastfeeding support. Journal of the American Dietetic Association, 108(7), 1221-25.

Coast Guard Commandant Instruction 1000.9. (September 2011). Pregnancy in the Coast Guard.

Department of Defense Instruction (DoDI) Number 1010.10. (28 April 2014). Health Promotion and Disease Prevention.

Eidelman, A., \& Schanler, R. (2012). Breastfeeding and the use of human milk. Pediatrics, 129(3), 827-841. doi: 10.1542/peds.2011-3552

Marine Corps Order (MCO) 5000.12E Section 15.8 MARADMIN 358/07 (December 2004).

National Center for Veterans Analysis and Statistics (November 2011). America's Women Veterans: Military Service History and VA Benefit Utilization Statistics. National Center for Veterans Analysis and Statistics, Department of Veterans Affairs, Washington, DC. Navy Instruction (OPNAVINST) 6000.1c. and BUMEDINST 6000.14 (14 June 2007). Navy Guidelines Concerning Pregnancy and Parenthood. 
Nunnally, J. C., \& Bernstein, I. H. (1994). Psychometric Theory (3rd edition.). New York, NY: McGraw-Hill.

Roche-Paull, R. (2010). Breastfeeding in combat boots: A survival guide to successful breastfeeding while serving in the military. Amarillo: Hale Publishing, L.P. TRICARE Policy Manual 6010.57-M (1 February 2008). Breast Pumps. Authority: 32 CFR $199.4(d)(1)$

U.S. Department of Health and Human Services, Office of the Surgeon General. (2011). The surgeon general's call to action to support breastfeeding. Retrieved from U.S. Department of Health and Human Services website: http://www.surgeongeneral.gov 
Tables

Table 1

Summary of Military Breastfeeding Policies

\begin{tabular}{|c|c|c|}
\hline $\begin{array}{l}\text { Branch of } \\
\text { Service }\end{array}$ & Work accommodations & Deployments \\
\hline Air Force & $\begin{array}{l}\text { Pump breaks: } 15-30 \text { minutes every } 3-4 \text { hours } \\
\text { In a room or area that provides adequate privacy and } \\
\text { cleanliness, if available. Restrooms should not be } \\
\text { considered appropriate location for pumping. } \\
\text { Mothers supply equipment to pump and store milk. }\end{array}$ & $\begin{array}{l}\text { Deferred for } 6 \text { months } \\
\text { postpartum. } \\
\text { May be deferred for } 12 \\
\text { months at the } \\
\text { commander's discretion. }\end{array}$ \\
\hline Army & $\begin{array}{l}\text { No specific guidelines or official lactation policy in } \\
\text { place for AD mothers. } \\
\text { Memorandum for commanders that outlines a plan } \\
\text { for active duty member to pump while at work. } \\
\text { - Urges member and supervisor/commander to work } \\
\text { together to develop a plan to pump/breastfeed after } \\
\text { returning to duty. }\end{array}$ & $\begin{array}{l}\text { Deferred from } 4 \text { to } 6 \\
\text { months postpartum in } \\
2008 .\end{array}$ \\
\hline Navy & $\begin{array}{l}\text { Policy in place stating facilities must have a clean, } \\
\text { secluded place available to breastfeeding/pump at } \\
\text { work as well as access to cold storage of expressed } \\
\text { milk. Time allowed to BF/pump varies and is } \\
\text { coordinated b/w member and supervisor. }\end{array}$ & $\begin{array}{l}\text { Deferred to } 12 \text { months } \\
\text { postpartum. }\end{array}$ \\
\hline Marines & $\begin{array}{l}\text { Policy in place stating that at minimum a women } \\
\text { choosing to breastfeed should be allowed a clean, } \\
\text { secluded space in which to do so. }\end{array}$ & $\begin{array}{l}\text { Deferred to } 6 \text { months } \\
\text { postpartum. }\end{array}$ \\
\hline Coast Guard & $\begin{array}{l}\text { Policy that specifies that a private room is required } \\
\text { for breastfeeding/pumping. No guidance on breaks } \\
\text { or length of time to pump. } \\
* \text { Male or female member have the option of taking a } \\
\text { one-time } 2 \text {-year, unpaid separation from active duty } \\
\text { to care for a newborn, with return to the same pay } \\
\text { grade and benefits. }\end{array}$ & $\begin{array}{l}\text { Deferment for } 6 \text { months } \\
\text { postpartum. }\end{array}$ \\
\hline
\end{tabular}

Sources: Information from DoD websites and Breastfeedingincombatboots.com/military-policies/

1. Air Force Instruction (AFI) 44-102. Section 4.16: Breastfeeding and Breast Pumping (1 May 2006, revised 20 Jan 2012). Medical Care Management by order of the Secretary of the Air Force.

2. Army Regulation (AR) 40-501 (2007). Standards of Medical Fitness, Pregnancy and Postpartum Profiles. AR 614-30: Assignments, Details, and Transfers, Overseas Service in Pregnancy. 600-8-10: Leaves and Passes, Postpartum Convalescent Leave.

3. Navy Instruction (OPNAVINST) 6000.1c. and BUMEDINST 6000.14. Navy Guidelines Concerning Pregnancy and Parenthood. 14 June 2007.

4. Marine Corps Order (MCO) 5000.12E Section 15. 8. MARADMIN 358/07. December 2004.

5. Coast Guard Commandant Instruction (COMDTINST M1000.6A). Pregnancy in the Coast Guard. 29 Sept 2011 
Table 2

Participant Demographics (Active Duty Females $N=318$ )

\begin{tabular}{|c|c|c|c|}
\hline Variables & $n(\%)$ & Variables & $n(\%)$ \\
\hline Age (years) & & Branch & \\
\hline $21-29$ & $164(51.4 \%)$ & Air Force & $120(37.7 \%)$ \\
\hline $30-39$ & $142(44.5 \%)$ & Army & $116(36.5 \%)$ \\
\hline $40-49$ & $12(3.8 \%)$ & Navy & $51(16.0 \%)$ \\
\hline \multirow[t]{3}{*}{ Missing } & $0(0 \%)$ & Marine Corps & $18(5.7 \%)$ \\
\hline & & Coast Guard & $13(4.1 \%)$ \\
\hline & & Missing & $0(0 \%)$ \\
\hline \multicolumn{4}{|l|}{ Ethnicity } \\
\hline Caucasian & $241(75.8 \%)$ & Duty Location & \\
\hline Hispanic & $38(12.0 \%)$ & Stateside & $260(81.8 \%)$ \\
\hline $\mathrm{AA}$ & $16(5.0 \%)$ & Overseas & $57(17.9 \%)$ \\
\hline Asian & $4(1.3 \%)$ & Missing & $1(0.3 \%)$ \\
\hline Other & $14(4.4 \%)$ & & \\
\hline \multirow[t]{2}{*}{ Missing } & $5(1.6 \%)$ & & \\
\hline & & Primary Job Function & \\
\hline Education & & Administrative & $174(54.7 \%)$ \\
\hline High School & $19(6.0 \%)$ & Non-admin & $138(43.4 \%)$ \\
\hline Some College & $113(35.5 \%)$ & Missing & $6(1.9 \%)$ \\
\hline College Graduate & $107(33.6 \%)$ & & \\
\hline Post Graduate & $78(24.5 \%)$ & & \\
\hline Missing & $1(0.3 \%)$ & & \\
\hline WIC Eligible & & Able to meet BF goals & \\
\hline Yes & $41(12.9 \%)$ & Yes & $205(64.5 \%)$ \\
\hline Yes, but did not use & $17(5.3 \%)$ & No & $107(33.6 \%)$ \\
\hline No & $256(80.5 \%)$ & Missing & $6(1.9 \%)$ \\
\hline \multirow[t]{2}{*}{ Missing } & $4(1.3 \%)$ & & \\
\hline & & Reasons did not meet BF goals & \\
\hline Rank & & Lack of support & $45(14.2 \%)$ \\
\hline Officer & $132(41.5 \%)$ & Separation from baby & $40(12.6 \%)$ \\
\hline Enlisted & $182(57.2 \%)$ & Milk supply issues & $43(13.5 \%$ \\
\hline \multirow[t]{3}{*}{ Missing } & $4(1.3 \%)$ & Baby latch issues & $5(1.6 \%)$ \\
\hline & & Other & $25(7.9 \%)$ \\
\hline & & Missing & $160(50.3 \%)$ \\
\hline
\end{tabular}


Table 3

Estimated Marginal Means of WBSS Scores for Rank and Branch of Service $95 \%$ Confidence Interval

Rank while breastfeeding Officer Enlisted Mean Std. Error Lower Bound Upper Bound

Military Branch Air Force Army 
Figures

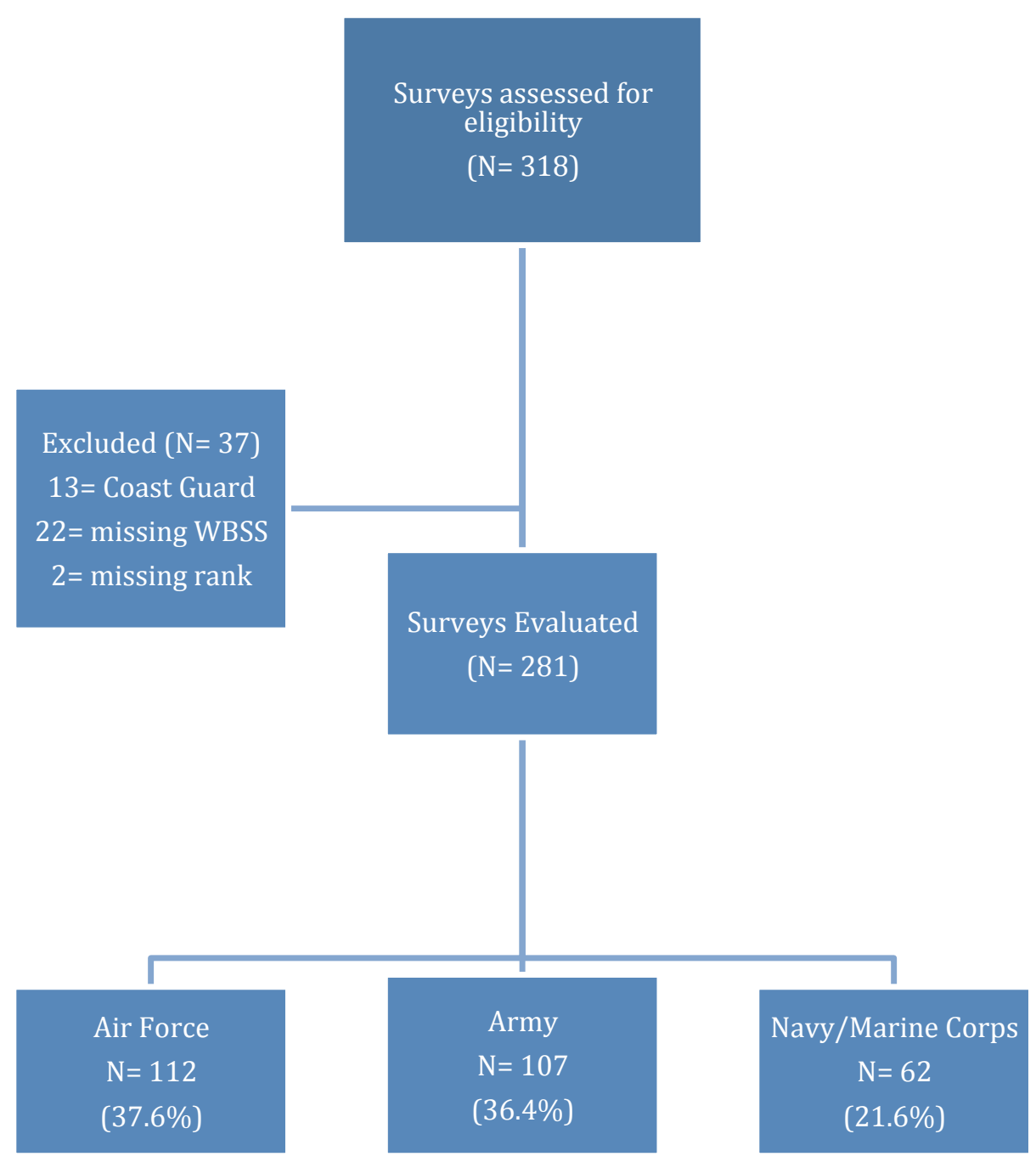

Figure 1. Consort diagram for loss of sample size in 2-way ANOVA. 


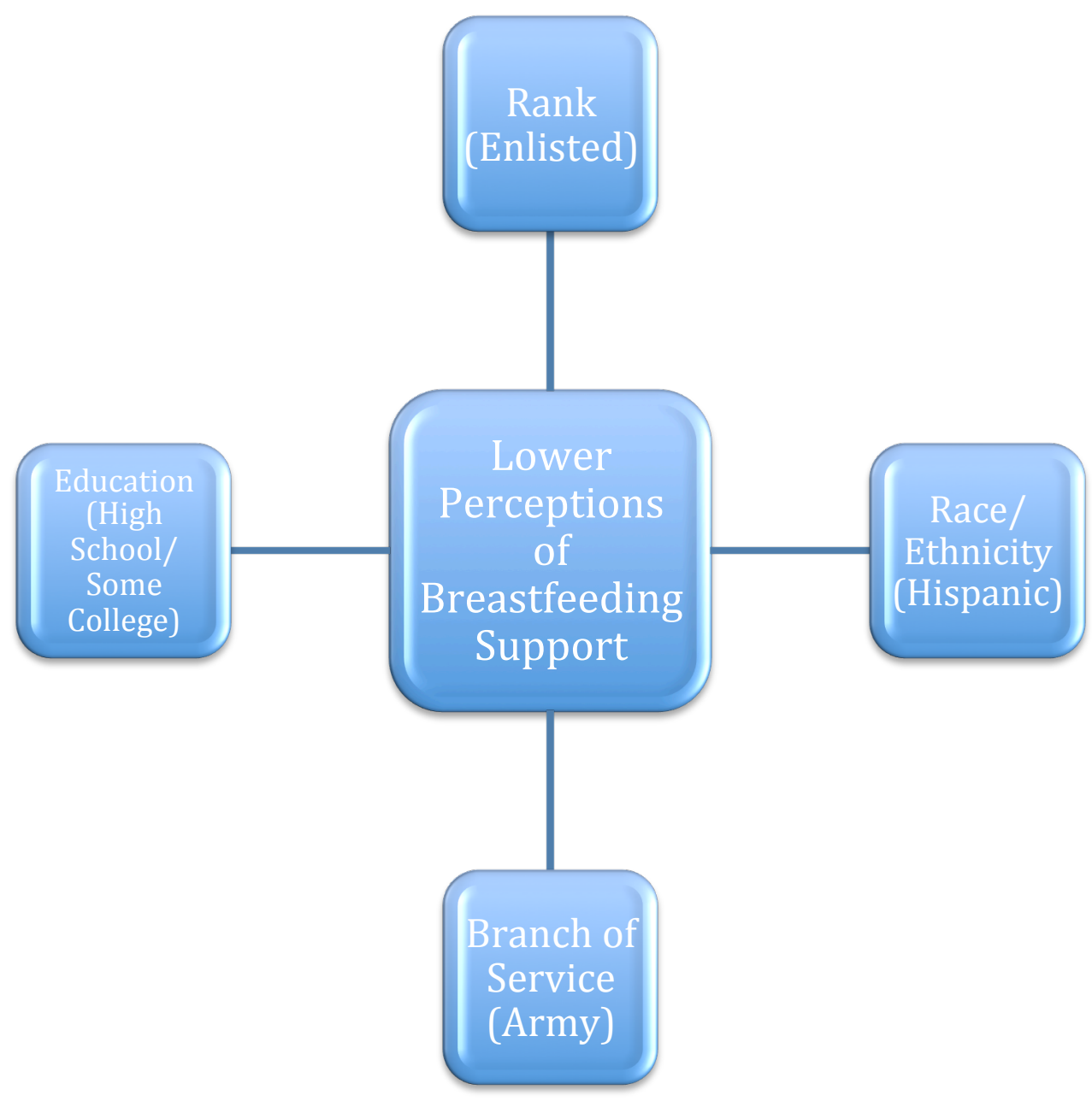

Figure 2. Demographic characteristics of active duty women with lower perceptions of breastfeeding support. 
Table 1

Healthy People 2020 Breastfeeding Objectives

\begin{tabular}{|l|l|l|}
\hline Any Breastfeeding & 2009 Rates & 2020 Goals \\
\hline EVER & $77.0 \%$ & $81.9 \%$ \\
\hline At 6 months & $47 \%$ & $60.6 \%$ \\
\hline At 1 year & $26 \%$ & $34.1 \%$ \\
\hline Exclusive Breastfeeding & & \\
\hline To 3 months & $33.5 \%$ & $44.3 \%$ \\
\hline To 6 months & $13.8 \%$ & $23.7 \%$ \\
\hline Worksite Lactation & $25 \%$ & $38 \%$ \\
\hline support & & \\
\hline
\end{tabular}

Source: Data retrieved from HealthyPeople.gov and the Centers for Disease Control National Immunization Survey, 2009 (www.CDC.gov). 
Table 2

Morbidity Risk Reduction for Breastfed Infants and Children

\begin{tabular}{|c|c|}
\hline Infant/Child Condition & $\begin{array}{l}\text { \% Lower } \\
\text { Risk * }\end{array}$ \\
\hline Recurrent Otitis Media & $77 \%$ \\
\hline Upper Respiratory Tract Infection & $63 \%$ \\
\hline Lower Respiratory Tract Infection & $77 \%$ \\
\hline Asthma & $40 \%$ \\
\hline Gastroenteritis & $64 \%$ \\
\hline Atopic Dermatitis & $42 \%$ \\
\hline Obesity & $24 \%$ \\
\hline Type 1 Diabetes & $30 \%$ \\
\hline Type 2 Diabetes & $40 \%$ \\
\hline SIDS & $36 \%$ \\
\hline
\end{tabular}

Source: American Academy of Pediatrics Policy Statement: Breastfeeding and the Use of Human Milk (2012).

* \% of lowered risk for infant and childhood illnesses vary according to exclusivity and duration of breastfeeding. 
Table 3

Summary of Military Breastfeeding Policies

\begin{tabular}{|c|c|c|}
\hline $\begin{array}{l}\text { Branch of } \\
\text { Service }\end{array}$ & Work accommodations & Deployments \\
\hline Air Force & $\begin{array}{l}\text { Pump breaks: } 15-30 \text { minutes every 3-4 hours } \\
\text { In a room or area that provides adequate privacy and } \\
\text { cleanliness, if available. Restrooms should not be } \\
\text { considered appropriate location for pumping. } \\
\text { Mothers supply equipment to pump and store milk. }\end{array}$ & $\begin{array}{l}\text { Deferred for } 6 \text { months } \\
\text { postpartum. } \\
\text { May be deferred for } 12 \\
\text { months at the } \\
\text { commander's discretion. }\end{array}$ \\
\hline Army & $\begin{array}{l}\text { No specific guidelines or official lactation policy in } \\
\text { place for AD mothers. } \\
\text { Memorandum for commanders that outlines a plan } \\
\text { for active duty member to pump while at work. } \\
\text { - Urges member and supervisor/commander to work } \\
\text { together to develop a plan to pump/breastfeed after } \\
\text { returning to duty. }\end{array}$ & $\begin{array}{l}\text { Deferred from } 4 \text { to } 6 \\
\text { months postpartum in } \\
2008 .\end{array}$ \\
\hline Navy & $\begin{array}{l}\text { Policy in place stating facilities must have a clean, } \\
\text { secluded place available to breastfeeding/pump at } \\
\text { work as well as access to cold storage of expressed } \\
\text { milk. Time allowed to BF/pump varies and is } \\
\text { coordinated b/w member and supervisor. }\end{array}$ & $\begin{array}{l}\text { Deferred to } 12 \text { months } \\
\text { postpartum. }\end{array}$ \\
\hline Marines & $\begin{array}{l}\text { Policy in place stating that at minimum a women } \\
\text { choosing to breastfeed should be allowed a clean, } \\
\text { secluded space in which to do so. }\end{array}$ & $\begin{array}{l}\text { Deferred to } 6 \text { months } \\
\text { postpartum. }\end{array}$ \\
\hline Coast Guard & $\begin{array}{l}\text { Policy that specifies that a private room is required } \\
\text { for breastfeeding/pumping. No guidance on breaks } \\
\text { or length of time to pump. } \\
\text { * Male or female member have the option of taking a } \\
\text { one-time 2-year, unpaid separation from active duty } \\
\text { to care for a newborn, with return to the same pay } \\
\text { grade and benefits. }\end{array}$ & $\begin{array}{l}\text { Deferment for } 6 \text { months } \\
\text { postpartum. }\end{array}$ \\
\hline
\end{tabular}

Sources: Information from DoD websites and Breastfeedingincombatboots.com/military-policies/

1. Air Force Instruction 44-102 (Section 4.15) by order of the Secretary of the Air Force, 1 May 2006.

Revised 20 January 2012.

2. Army Regulation 614-30, Table 3.1, Rule 33 and paragraph 3-8A(\%). 30 March 2010.

Section X of the TG281: Army Female Soldier Readiness Guide.

3. Navy Instruction (OPNAVINST) 6000.1c. and BUMEDINST 6000.14. Navy Guidelines Concerning Pregnancy and Parenthood. 14 June 2007.

4. Marine Corps Order (MCO) 5000.12E Section 15. 8. MARADMIN 358/07. December 2004.

5. Coast Guard Commandant Instruction (COMDTINST M1000.6A). Pregnancy in the Coast Guard. 29 Sept 2011 
Table 4

Participant Demographics (Active Duty Females $N=318$ )

\begin{tabular}{|c|c|c|c|}
\hline Variables & $n(\%)$ & Variables & $n(\%)$ \\
\hline Age (years) & & Branch & \\
\hline $21-29$ & $164(51.4 \%)$ & Air Force & $120(37.7 \%)$ \\
\hline $30-39$ & $142(44.5 \%)$ & Army & $116(36.5 \%)$ \\
\hline $40-49$ & $12(3.8 \%)$ & Navy & $51(16.0 \%)$ \\
\hline \multirow[t]{3}{*}{ Missing } & $0(0 \%)$ & Marine Corps & $18(5.7 \%)$ \\
\hline & & Coast Guard & $13(4.1 \%)$ \\
\hline & & Missing & $0(0 \%)$ \\
\hline \multicolumn{4}{|l|}{ Ethnicity } \\
\hline Caucasian & $241(75.8 \%)$ & Duty Location & \\
\hline Hispanic & $38(12.0 \%)$ & Stateside & $260(81.8 \%)$ \\
\hline $\mathrm{AA}$ & $16(5.0 \%)$ & Overseas & $57(17.9 \%)$ \\
\hline Asian & $4(1.3 \%)$ & Missing & $1(0.3 \%)$ \\
\hline Other & $14(4.4 \%)$ & & \\
\hline \multirow[t]{2}{*}{ Missing } & $5(1.6 \%)$ & & \\
\hline & & Primary Job Function & \\
\hline Education & & Administrative & $174(54.7 \%)$ \\
\hline High School & $19(6.0 \%)$ & Non-admin & $138(43.4 \%)$ \\
\hline Some College & $113(35.5 \%)$ & Missing & $6(1.9 \%)$ \\
\hline College Graduate & $107(33.6 \%)$ & & \\
\hline Post Graduate & $78(24.5 \%)$ & & \\
\hline Missing & $1(0.3 \%)$ & & \\
\hline WIC Eligible & & Able to meet BF goals & \\
\hline Yes & $41(12.9 \%)$ & Yes & $205(64.5 \%)$ \\
\hline Yes, but did not use & $17(5.3 \%)$ & No & $107(33.6 \%)$ \\
\hline No & $256(80.5 \%)$ & Missing & $6(1.9 \%)$ \\
\hline \multirow[t]{2}{*}{ Missing } & $4(1.3 \%)$ & & \\
\hline & & Reasons did not meet BF goals & \\
\hline Rank & & Lack of support & $45(14.2 \%)$ \\
\hline Officer & $132(41.5 \%)$ & Separation from baby & $40(12.6 \%)$ \\
\hline Enlisted & $182(57.2 \%)$ & Milk supply issues & $43(13.5 \%$ \\
\hline \multirow[t]{3}{*}{ Missing } & $4(1.3 \%)$ & Baby latch issues & $5(1.6 \%)$ \\
\hline & & Other & $25(7.9 \%)$ \\
\hline & & Missing & $160(50.3 \%)$ \\
\hline
\end{tabular}


Table 5

Demographic Characteristics by Rank

\begin{tabular}{|c|c|c|c|c|c|}
\hline Demographics & $\begin{array}{l}\text { Officer } \\
(n=182)\end{array}$ & $\begin{array}{l}\text { Enlisted } \\
(n=132)\end{array}$ & $\chi^{2}$ & $d f$ & $\begin{array}{c}\text { Chi-square } \\
p \text {-value }\end{array}$ \\
\hline \multicolumn{6}{|l|}{ Age } \\
\hline$<30$ & $39(29.5 \%)$ & $122(67.0 \%)$ & 43.04 & 1 & $<0.001$ \\
\hline$\geq 30$ & $93(70.5 \%)$ & $60(33.0 \%)$ & & & \\
\hline \multicolumn{6}{|l|}{ Ethnicity } \\
\hline White, Non-Hispanic & $103(80.5 \%)$ & $135(74.6 \%)$ & 1.91 & 2 & 0.19 \\
\hline Other, Non-Hispanic & $13(10.2 \%)$ & $20(11.0 \%)$ & & & \\
\hline Hispanic, all races & $12(9.4 \%)$ & $26(14.4 \%)$ & & & \\
\hline \multicolumn{6}{|l|}{ Education } \\
\hline HS/Some College & $0(0 \%)$ & $128(70.3 \%)$ & 164.57 & 2 & $<0.001$ \\
\hline College Graduate & $66(50.4 \%)$ & $41(22.5 \%)$ & & & \\
\hline Graduate Degree & $65(49.6 \%)$ & $13(7.1 \%)$ & & & \\
\hline \multicolumn{6}{|l|}{ WIC Eligible } \\
\hline Yes & $0(0 \%)$ & $57(31.8 \%)$ & 51.11 & 1 & $<0.001$ \\
\hline No & $131(100 \%)$ & $122(68.2 \%)$ & & & \\
\hline
\end{tabular}

Note. Numbers in parentheses indicate column percentages. 
Table 6

Demographic Characteristics by Branch of Service

\begin{tabular}{|c|c|c|c|c|c|c|}
\hline Demographics & Air Force & Army & $\begin{array}{c}\text { Navy/ } \\
\text { Marines }\end{array}$ & $\chi^{2}$ & $d f$ & $\begin{array}{c}\text { Chi- } \\
\text { square } \\
p \text {-value }\end{array}$ \\
\hline \multicolumn{7}{|l|}{ Age } \\
\hline$<30$ & $54(45.0 \%)$ & $66(56.9 \%)$ & $37(53.6 \%)$ & 3.51 & 2 & 0.087 \\
\hline$\geq 30$ & $66(55.0 \%)$ & $50(43.1 \%)$ & $32(46.4 \%)$ & & & \\
\hline \multicolumn{7}{|l|}{ Ethnicity } \\
\hline White, Non-Hispanic & $96(82.1 \%)$ & $78(67.8 \%)$ & $55(80.9 \%)$ & 9.50 & 4 & 0.025 \\
\hline Other, Non-Hispanic & $11(9.4 \%)$ & $15(13.0 \%)$ & $8(11.8 \%)$ & & & \\
\hline Hispanic & $10(8.5 \%)$ & $22(19.1 \%)$ & $5(7.4 \%)$ & & & \\
\hline \multicolumn{7}{|l|}{ Education } \\
\hline HS/Some College & $42(35.3 \%)$ & $44(37.9 \%)$ & $39(56.5 \%)$ & 10.76 & 4 & 0.015 \\
\hline College Graduate & $42(35.3 \%)$ & $40(34.5 \%)$ & $21(30.4 \%)$ & & & \\
\hline Graduate Degree & $35(29.4 \%)$ & $32(27.6 \%)$ & $9(13.0 \%)$ & & & \\
\hline \multicolumn{7}{|l|}{ WIC Eligible } \\
\hline Yes & $16(13.3 \%)$ & $20(17.4 \%)$ & $21(30.9 \%)$ & 9.00 & 2 & 0.006 \\
\hline No & $104(86.7 \%)$ & $95(82.6 \%)$ & $47(69.1 \%)$ & & & \\
\hline
\end{tabular}

Note. Numbers in parentheses indicate column percentages. 
Table 7

Estimated Marginal Means of WBSS Scores for Rank and Branch of Service

\begin{tabular}{lcccc}
\hline & \multicolumn{3}{c}{$95 \%$ Confidence Interval } \\
Rank while breastfeeding & Mean & Std. Error & Lower Bound & Upper Bound \\
\cline { 2 - 5 }$\quad$ Officer & 54.62 & 1.634 & 51.405 & 57.839 \\
$\quad$ Enlisted & 47.12 & 1.211 & 44.732 & 49.498 \\
& & & & \\
Military Branch & & & & \\
$\quad$ Air Force & 53.96 & 1.438 & 51.131 & 56.794 \\
$\quad$ Army & 45.85 & 1.469 & 42.956 & 48.741 \\
Navy \& Marines & 52.80 & 2.254 & 48.358 & 57.232 \\
\hline
\end{tabular}


Table 8

WBSS scores per question and branch of service

\begin{tabular}{|c|c|c|c|c|c|c|}
\hline WBSS Questions & $\begin{array}{l}\text { Army } \\
(n=108)\end{array}$ & $\begin{array}{l}\text { Air } \\
\text { Force } \\
(n=113)\end{array}$ & $\begin{array}{l}\text { Navy } \\
(n=45)\end{array}$ & $\begin{array}{l}\text { Marines } \\
(\mathbf{n}=17)\end{array}$ & $\begin{array}{l}\text { CG } \\
(n=12)\end{array}$ & $\begin{array}{l}\text { Total } \\
(\mathrm{N}=295)\end{array}$ \\
\hline $\begin{array}{l}\text { 1) My co-workers agree that } \\
\text { breastfeeding is better for baby's } \\
\text { health than formula feeding }\end{array}$ & 4.89 & 5.56 & 5.28 & 4.78 & 4.92 & 5.20 \\
\hline $\begin{array}{l}\text { 2) I have supportive co-workers } \\
\text { who cover for me when I need to } \\
\text { pump my milk }\end{array}$ & 4.55 & 5.25 & 5.30 & 5.06 & 5.38 & 5.00 \\
\hline $\begin{array}{l}\text { 3) My co-workers do not make } \\
\text { fun of me when I sometimes leak } \\
\text { milk through my clothes }\end{array}$ & 4.41 & 5.37 & 4.52 & 4.35 & 5.46 & 4.83 \\
\hline $\begin{array}{l}\text { 4) Breastfeeding is common in } \\
\text { my workplace }\end{array}$ & 2.78 & 4.08 & 4.06 & 2.44 & 4.23 & 3.52 \\
\hline $\begin{array}{l}\text { 5) I have a breastfeeding } \\
\text { supportive supervisor }\end{array}$ & 4.50 & 5.24 & 4.86 & 4.67 & 5.85 & 4.90 \\
\hline $\begin{array}{l}\text { 6) My co-workers listen to me } \\
\text { talk about my breastfeeding } \\
\text { experience }\end{array}$ & 3.84 & 4.90 & 4.38 & 4.11 & 4.85 & 4.38 \\
\hline $\begin{array}{l}\text { 7) I feel comfortable taking } \\
\text { several breaks during work } \\
\text { hours to pump breast milk }\end{array}$ & 3.88 & 4.20 & 4.53 & 4.67 & 5.31 & 4.21 \\
\hline $\begin{array}{l}\text { 8) In my workplace, there is a } \\
\text { designated space (nursing room) } \\
\text { to nurse my baby or pump } \\
\text { breast milk }\end{array}$ & 2.61 & 3.07 & 4.58 & 2.17 & 5.54 & 3.20 \\
\hline $\begin{array}{l}\text { 9) I can easily find a quiet place } \\
\text { other than the bathroom at my } \\
\text { work to pump breast milk }\end{array}$ & 3.93 & 4.69 & 4.68 & 2.56 & 5.62 & 4.33 \\
\hline $\begin{array}{l}\text { 10) My workplace has a } \\
\text { refrigerator that I can use to } \\
\text { store my milk }\end{array}$ & 4.97 & 5.63 & 5.48 & 5.72 & 6.46 & 5.41 \\
\hline $\begin{array}{l}\text { 11) My workplace has a breast } \\
\text { pump for nursing mothers to use }\end{array}$ & 1.61 & 2.03 & 2.08 & 1.00 & 1.00 & 1.79 \\
\hline $\begin{array}{l}\text { 12) My workplace has an on-site } \\
\text { daycare (i.e. CDC) }\end{array}$ & 3.65 & 4.01 & 3.16 & 3.89 & 1.46 & 3.63 \\
\hline
\end{tabular}

Note. See Figure 7 for bar graph of data. 


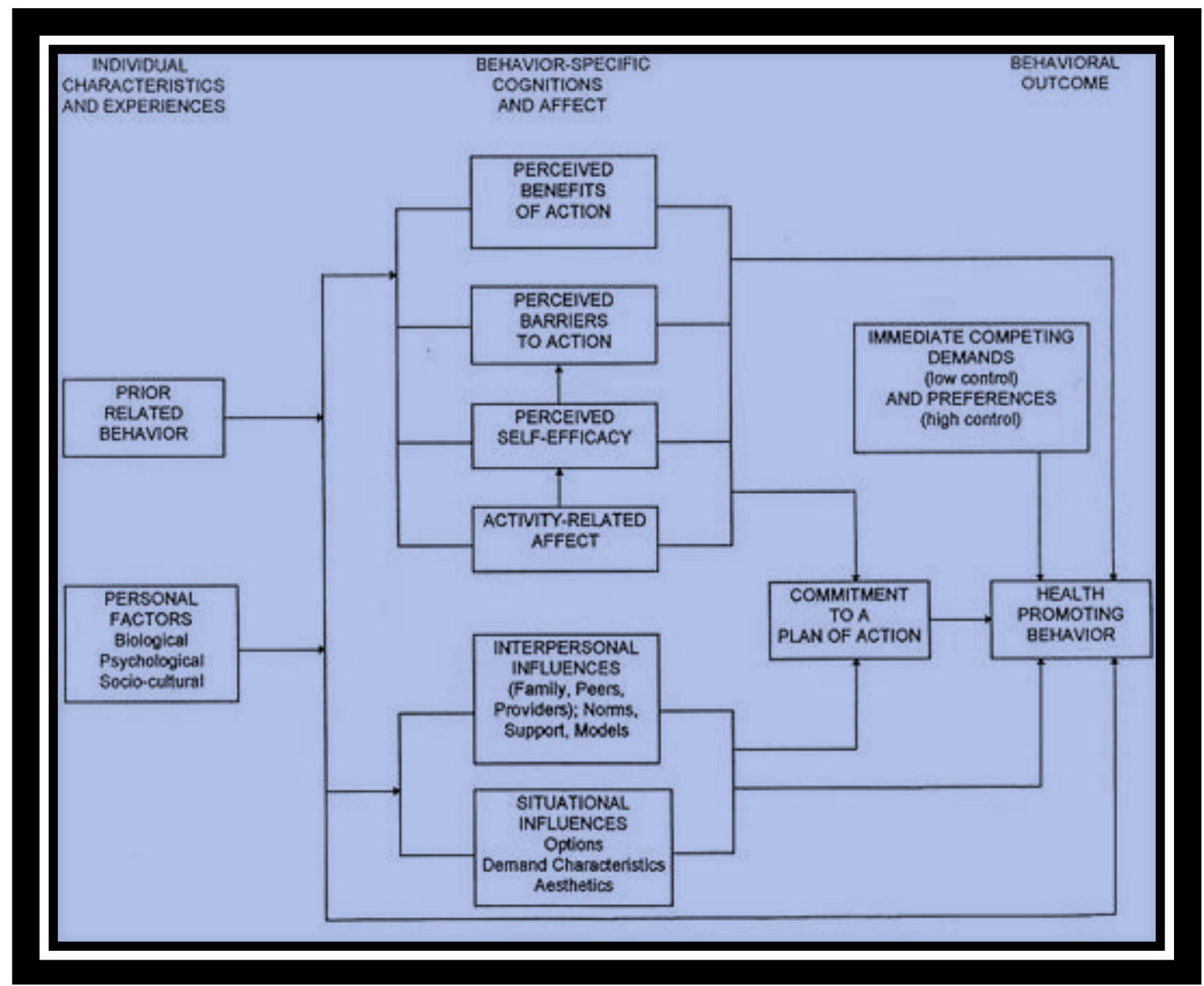

Figure 1. Visual display of Pender's Health Promotion Model (George, 2010). 


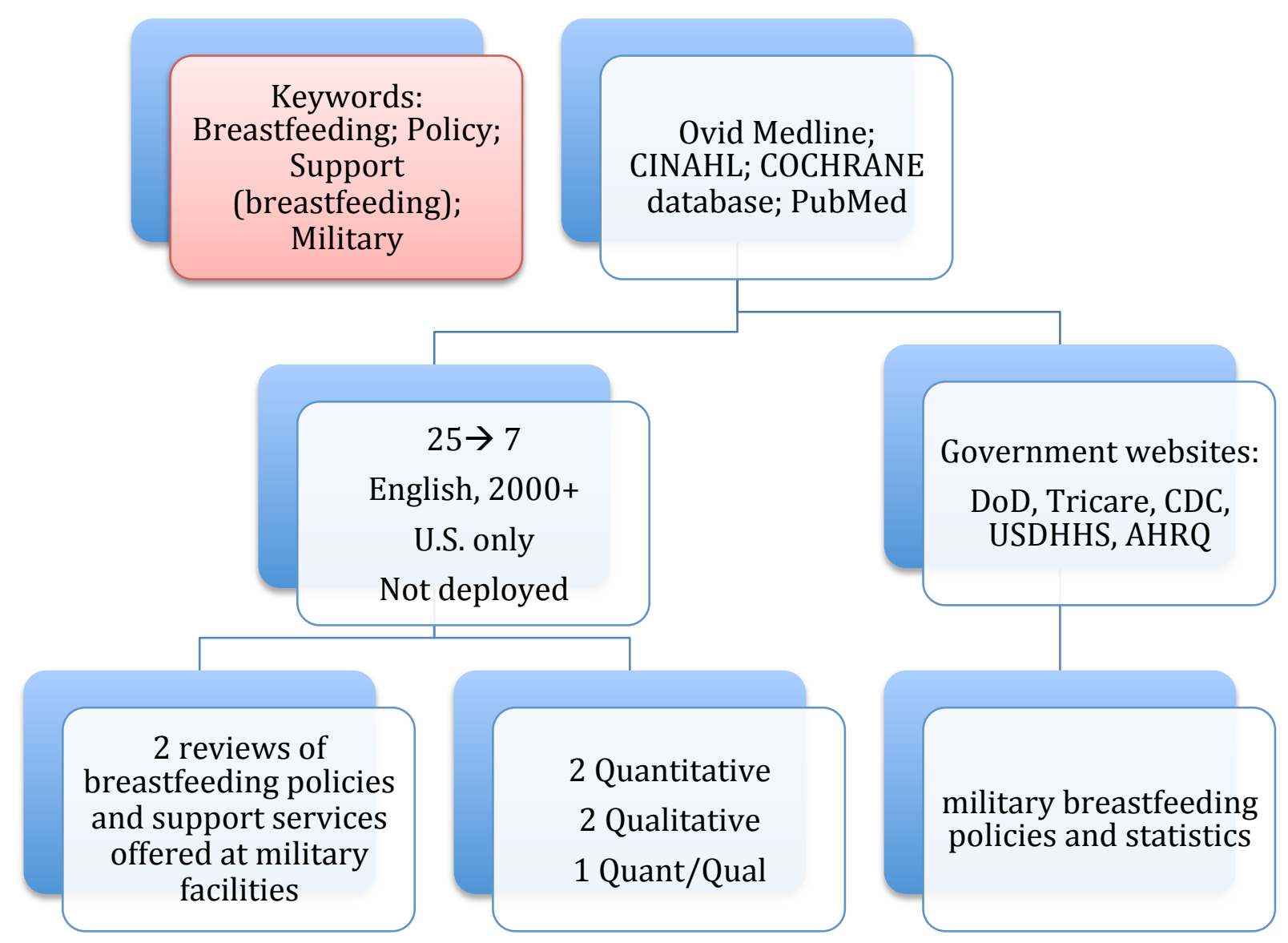

Figure 2. Literature review summary. 


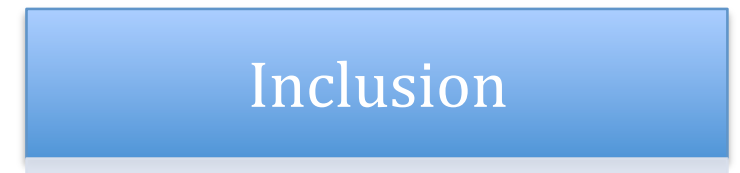

- Active duty military at time of breastfeeding

- Any branch of service (Army, Navy, AF, Marines, Coast Guard)

- Any career field

- Breastfed at least one child between 1 January 2010 to 30 September 2013

\section{Exclusion}

- Civilian, military dependent

- Military Guard or Reserve status at time of breastfeeding

- Breastfed prior to 1 January 2010 or after 30 September 2013

Figure 3. Summary of participant inclusion and exclusion criteria. 


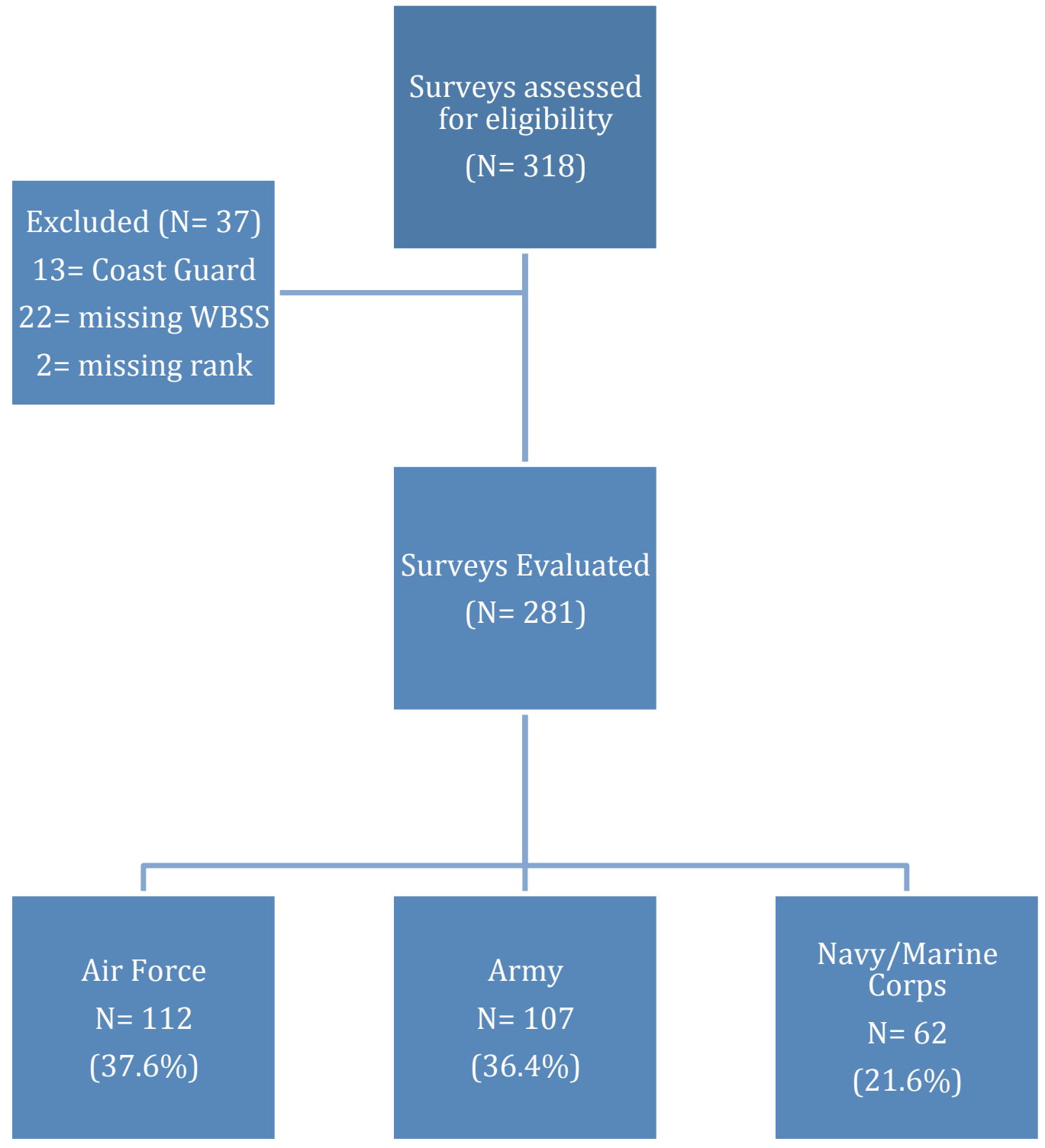

Figure 4. Consort diagram for loss of sample size in 2-way ANOVA. 


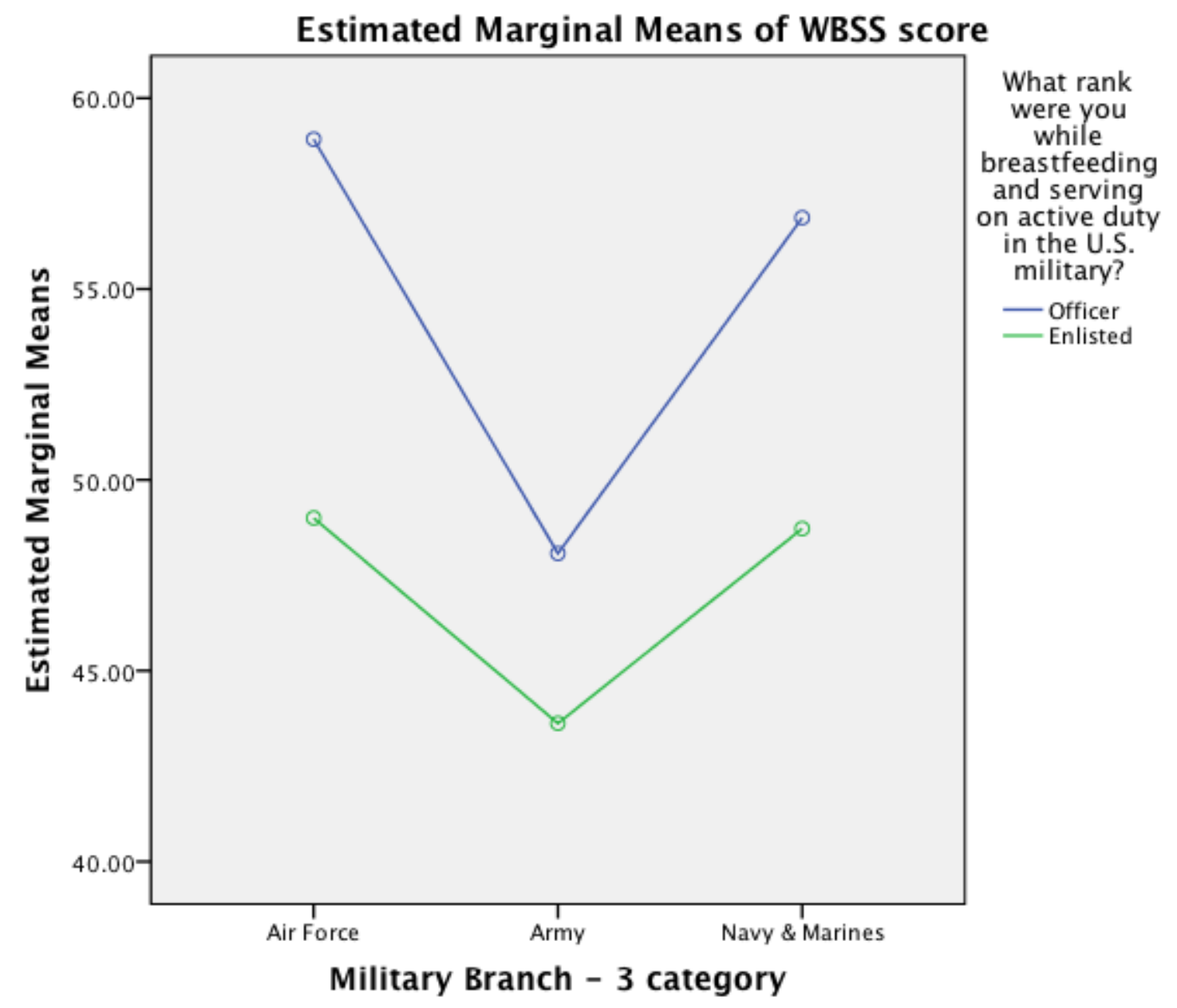

Figure 5. Line graph depicting the estimated marginal means of WBSS scores between rank and branch of service. 
My workplace has an on-site daycare (i.e. CDC)

My workplace has a breast pump for nursing mothers to use

My workplace has a refrigerator that I can use to store my milk

I can easily find a quiet place other than the bathroom at my work to pump breast milk

In my workplace, there is a designated space (nursing room) to nurse my baby or pump breast milk

I feel comfortable taking several breaks during work hours to pump breast milk

My co-workers listen to me talk about my breastfeeding experience

I have a breastfeeding supportive supervisor

Breastfeeding is common in my workplace

My co-workers do not make fun of me when I sometimes leak milk through my clothes

I have supportive co-workers who cover for me when I need to pump my milk

My co-workers agree that breastfeeding is better for baby's health than formula feeding

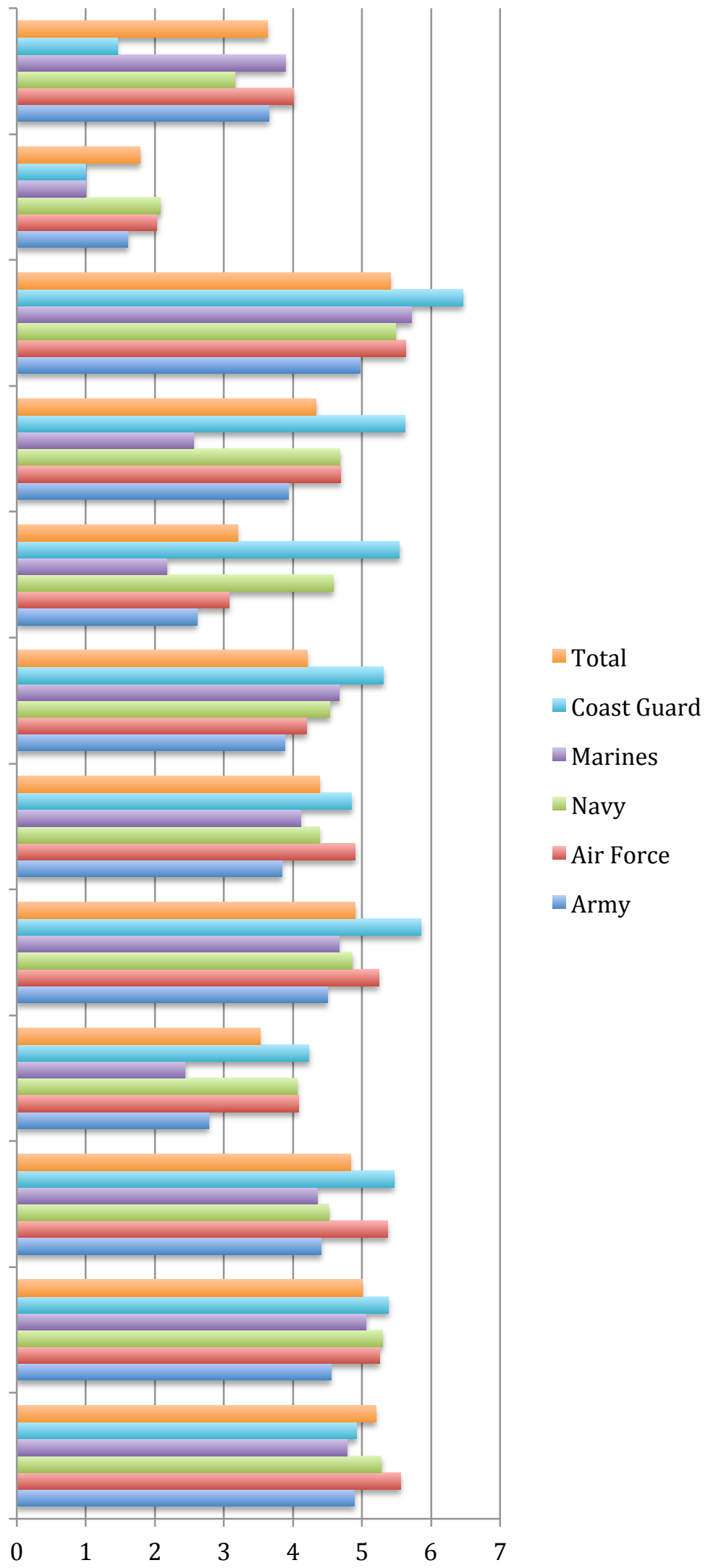

Figure 6. Average WBSS scores by question and branch of service. Note: Total scores are combined average WBSS scores for all branches of service. 


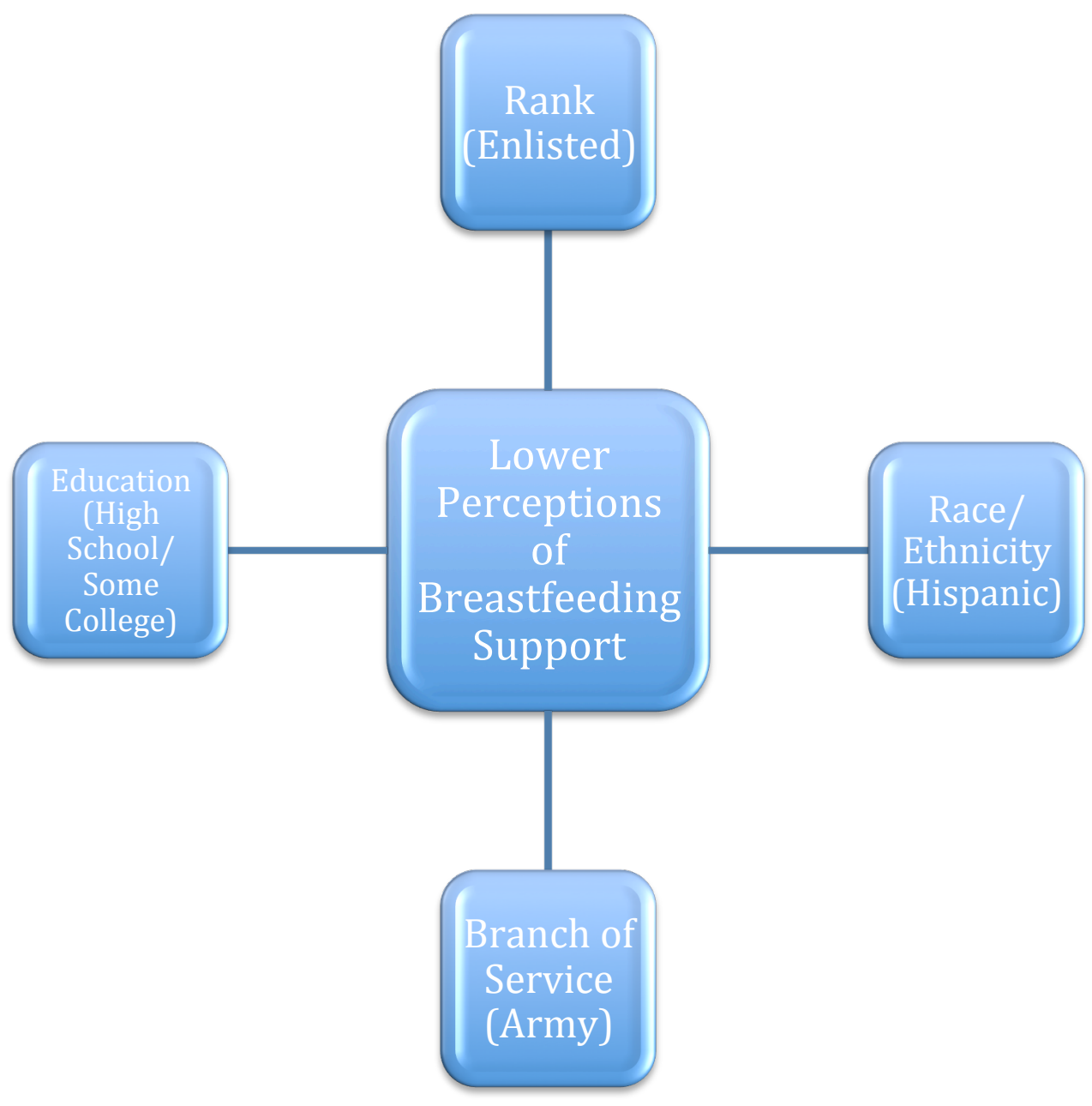

Figure 7. Demographic characteristics of active duty women with lower perceptions of breastfeeding support. 